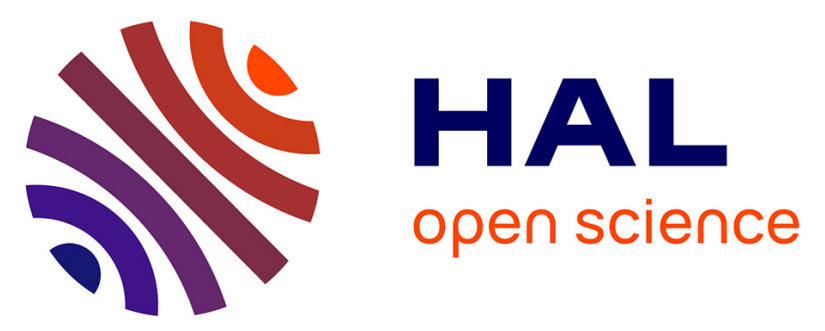

\title{
Procedures for leukocytes isolation from lymphoid tissues and consequences on immune endpoints used to evaluate fish immune status: A case study on roach (Rutilus rutilus)
}

Hakim Chouki Samai, Damien Rioult, Anne Bado-Nilles, Laurence Delahaut, Justine Jubreaux, Alain Geffard, Jean-Marc Porcher, Stéphane Betoulle

\section{To cite this version:}

Hakim Chouki Samai, Damien Rioult, Anne Bado-Nilles, Laurence Delahaut, Justine Jubreaux, et al.. Procedures for leukocytes isolation from lymphoid tissues and consequences on immune endpoints used to evaluate fish immune status: A case study on roach (Rutilus rutilus). Fish and Shellfish Immunology, 2018, 74, pp.643-657. 10.1016/j.fsi.2017.12.040 . ineris-01863329

HAL Id: ineris-01863329

https://hal-ineris.archives-ouvertes.fr/ineris-01863329

Submitted on 28 Aug 2018

HAL is a multi-disciplinary open access archive for the deposit and dissemination of scientific research documents, whether they are published or not. The documents may come from teaching and research institutions in France or abroad, or from public or private research centers.
L'archive ouverte pluridisciplinaire HAL, est destinée au dépôt et à la diffusion de documents scientifiques de niveau recherche, publiés ou non, émanant des établissements d'enseignement et de recherche français ou étrangers, des laboratoires publics ou privés. 


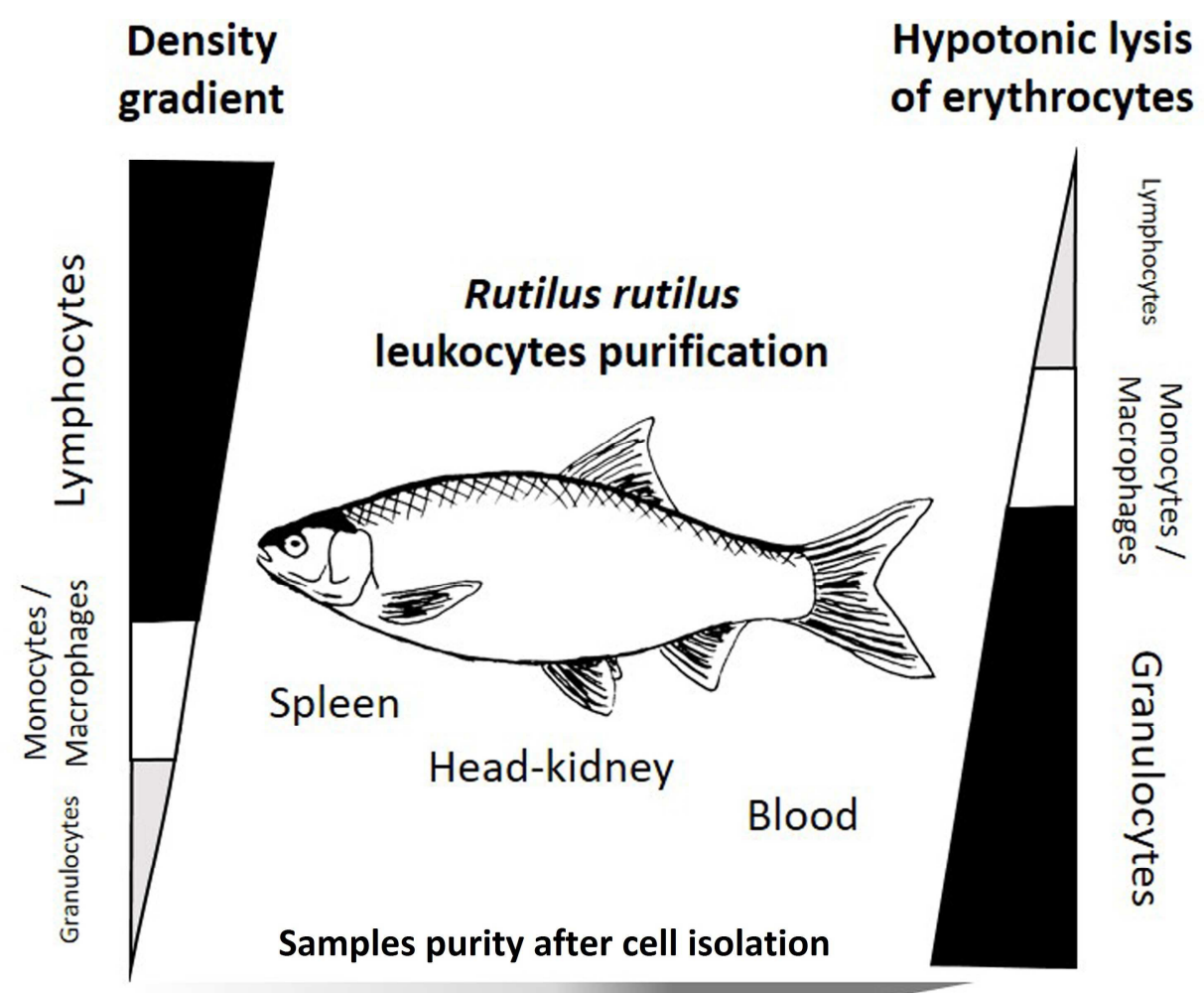

Variability in leukocytes subtypes distributions before and after cell incubation 
2 endpoints used to evaluate fish immune status: a case study on roach (Rutilus rutilus)

4 Hakim C. Samaï*1, Damien Rioult ${ }^{2}$, Anne Bado-Nilles ${ }^{3}$, Laurence Delahaut ${ }^{1}$, Justine 5 Jubréaux ${ }^{1}$, Alain Geffard ${ }^{1}$, Jean-Marc Porcher $^{3}$ \& Stéphane Betoulle ${ }^{1}$.

$6{ }^{1}$ Université de Reims Champagne-Ardenne, UMR-I 02 SEBIO Stress Environnementaux et 7 Biosurveillance des milieux aquatiques, SFR Condorcet FR CNRS 3417, UFR Sciences

$8 \quad$ Exactes et Naturelles, BP 1039, 51687 Reims Cedex 2, France

${ }^{2}$ Université de Reims Champagne-Ardenne/INERIS, Plateau technique mobile en cytométrie environnementale MOBICYTE, UFR des Sciences Exactes et Naturelles, BP 1039, 51687

Reims Cedex 2, France

${ }^{3}$ Institut National de l'Environnement Industriel et des Risques, UMR-I 02 SEBIO Stress Environnementaux et Biosurveillance des milieux aquatiques, 60550 Verneuil-en-Halatte, France

* Corresponding author :

Hakim-Chouki SAMAI

Phone: 33.3.26.01.83.18

Email: samai.hakim.chouki@gmail.com

Keywords: fish, leukocytes, cell isolation, density gradient, erythrocytes lysis, immunity.

Abbreviations: DCFH-DA: 2',7'-dichlorofluorescin diacetate; DG: density gradient; FCS: foetal calf serum; HL: hypotonic lysis, P/S: Penicillin/Streptomycin; PBS: Phosphate Buffer Saline ; PI: propidium iodide; ROS: reactive oxygen species; SI: stimulation index. 
25

The effects of two protocols (density gradient versus hypotonic lysis) used for leukocyte isolation from three major lymphoid tissue of fish (head-kidney, spleen and blood) were examined on some cell functional activities (tissue leucocytes distributions, phagocytosis, basal and burst oxidative activities) classically used to estimate the fish immune status. Experiments were conducted on roach (Rutilus rutilus), a cyprinid fish model often studied in different eco-physiological contexts (aquaculture, ecotoxicology...). All of immune endpoints were assessed either immediately after cell isolation or after a $12 \mathrm{~h}$ of incubation in order to observe if a post-isolation incubation may influence the leukocytes activities.

Compared to the density gradient, hypotonic lysis is associated with granulocytes enrichments of cell suspensions. This is particularly true for leukocyte suspensions isolated from head kidney where granulocytes are naturally abundant. However, important variabilities in leucocyte distributions were observed in head kidney and spleen cells samples obtained by the use of hypotonic lysis for two incubation conditions used (no incubation or $12 \mathrm{~h}$ of incubation at $4{ }^{\circ} \mathrm{C}$ ). The density gradient protocol leads to a transitory increase in basal ROS production in spleen lymphocytes and macrophages The blood leukocytes isolated by this same method exhibit high basal oxidative activities after $12 \mathrm{~h}$ of incubation at $4^{\circ} \mathrm{C}$ and for the three leukocyte types (lymphocytes, monocytes and granulocytes). The hypotonic lysis is associated with an increase in PMA-induced ROS production especially in head kidney leukocytes. The increases in cell oxidative activities are consistent with increases in granulocyte proportions observed in leukocyte suspensions obtained by hypotonic lysis. Finally, the two protocols have no effect on leucocyte mortality and phagocytic activity.

Within limits of our experimental conditions, the spleen is the organ whose leucocyte oxidative activities (stimulated or not) are only slightly influenced by the methods used for leukocyte isolation. This is also the case for the anterior kidney, but for this tissue, it is necessary to incubate the isolated cells for $12 \mathrm{~h}$ at $4{ }^{\circ} \mathrm{C}$ before functional analyses. 
allows to isolate a greater variety of leukocytes types whereas the density gradient used ensures a better stability of cells distributions over time. However, for the same fish species and for the same tissue, the method used to isolate leukocytes influences results and must be taken into consideration during acquired data analysis for evaluation of fish immune status.

\section{Introduction}

Immunity has an integrative and central role in physiological regulations of organisms. Even if the term of immunocompetence was not well defined yet, it represents an average value of the immunity of an organism exposed to multiple parasites and stressors [1]. It is important but not easy to evaluate immunocompetence of organisms in their own environment. As all the vertebrates, the fish immune system is a complex, multifaceted and coordinated system working to destroy pathogens and also to maintain organism integrity. Thus, it must be emphasized that a measure of a single immune endpoints is not sufficient to capture the complexity of an immune response and to estimate the immune status of an organism.

As observed in all vertebrates, fish immune response implicate various cell types. These cellular defence systems corresponds to phagocytic cells similar to macrophages, neutrophils and natural killer (NK) cells, as well as T and B lymphocytes [2-4]. The main leucocyte responses often studied in fish immune ecophysiology are represented by intracellular reactive oxygens species production associated with pathogens phagocytosis [5-8] In fish immune ecophysiology, other cellular parameters as for instance apoptosis or lysosomal activity may complete these two main functions by the use of flow cytometry techniques [9-13]. Flow cytometry provides multi-parametric data that can be used in simultaneously analysis of numerous cell properties. By this technique, it is also possible to differentiate lymphocytes, monocytes/macrophages and granulocytes and to link responses of observed cellular activities with the different types of cells present in the tissue sample. Such analysis can be perform on many different lymphoid tissues (spleen, head-kidney, blood). All of these multi-parametric 
to the state of their living environment.

To perform such observations on immune cells, all tissue samples must be in a single cell suspension. Indeed, before cytometric measurements of functional cellular activities, the major initial methodological step is to collect the leukocytes from the different lymphoid tissues. The erythrocyte presence in biological samples may create another difficulty especially in case of species as teleost fish which possess nucleated red blood cells. Samples contaminations by erythrocytes may compromise cytometric analysis.

The dual necessity to obtain single cell suspensions of leukocytes with no erythrocytes contaminations constitutes the actual main methodological constraint to evaluate fish immune responses.

Among the different techniques, hypertonic lysis and density gradient are the two main way used in literature to separate leukocytes from erythrocytes. Many isolation methods of vertebrates leucocytes exists and were extensively studied as hypertonic shock using ammonium chloride [14], positive selection [15], self-generating gradient [16,17], cryopreservation [18], adherence and agglutination [19] and density gradient. The use of Ficoll ${ }^{\circledR}$ or Percoll ${ }^{\circledR}$ to constitute density gradients is one of the most common isolation procedure for vertebrate leucocytes [20]. However, Ficoll@ gradients may bring out some alterations in cell responses and cell surface markers in addition to cell morphological changes [21].

Purification of mammalian leukocytes by erythrocyte lysis with hypertonic ammonium chloride was usually used and is efficient in case of lysis of mammalian non-nucleated erythrocytes. However, removing erythrocytes from fish leukocyte suspensions by the use of ammonium chloride was not successful as the presence of nuclei in teleost erythrocytes may preclude lysis [22]. In 2001, another technique corresponding to an hypotonic lysis of teleost erythrocytes in peripheral blood and pronephrotic leukocytes samples was proposed by 
immune responses need to be evaluated [24-27].

104

105

But whatever the methodology used in fish immunological investigations (density gradient, hypotonic lysis), it is important to estimate its influence on acquired data in terms of leukocytes activities and distributions.

Hence, we compared here the effects of two protocols (density gradient versus hypotonic lysis) for leukocyte isolation from three major lymphoid tissue of fish (head-kidney, spleen and blood) on some cell functional activities (tissue leucocytes distributions, phagocytosis, basal and burst oxidative activities) classically used to estimate the fish immune status. Experiments were conducted on roach (Rutilus rutilus), a cyprinid fish model often studied in different eco-physiological contexts (aquaculture, ecotoxicology...). All of these immune endpoints were assessed either immediately after cell isolation or after a $12 \mathrm{~h}$ of incubation in order to observe if a post-isolation incubation may influence the leukocytes activities [28].

\section{Materials and methods:}

\subsection{Chemicals and reagents:}

Culture media Leibovitz L15, penicillin and streptomycin (P/S), heparin, propidium iodide (PI), 2',7'-dichlorofluorescin Diacetate (DCFH-DA) and phorbol 12-myristate 13-acetate (PMA) were purchased from Sigma-Aldrich. Ficoll® (Ficoll@-Paque PLUS) was obtained from GE Healthcare, fetal calf serum (FCS) from Biochrom AG and fluorescent latex beads from Biovalley. Phosphate Buffer Saline (PBS 10X) was prepared as described by Dulbecco and Vogt (1954).

\subsection{Fish:}

Adult roach (Rutilus rutilus: $12 \pm 0.5 \mathrm{~cm}$ length and $12.8 \pm 1.25 \mathrm{~g}$ weight; Age: $2+$ ) were purchased from a local fish producer (Saint-Mard-sur-le-Mont, France) and acclimated in laboratory in $400 \mathrm{~L}$ tanks with continuously filtered water for a period of 3 weeks before 
physical-chemical conditions record and maintain (pH: $7.19 \pm 0.26$; Conductivity: $237 \pm 28$ $\mu \mathrm{S}$; Oxygen saturation: $9.67 \pm 0.46 \mathrm{mg} / \mathrm{L}$; Temperature: $10.4 \pm 0.45{ }^{\circ} \mathrm{C}$ and photoperiod of 12 hours dark/light). Experiments were conducted in April corresponding to reproduction period in the roach life cycle [30]. Protocols of fish and experimentation were reviewed and approved in accordance with the standards recommended by the Guide for the Care and Use of Laboratory Animals and Directive 63/2010/EU.

\subsection{Lymphoid tissues collection:}

Peripheral blood from ten fish was sampled from caudal vein with $1 \mathrm{~mL}$ syringe containing 50 $\mu \mathrm{L}$ of heparin $(500 \mathrm{UI} / \mathrm{mL})$. Each sample was then diluted in $\mathrm{L} 15$ medium containing 500 $\mathrm{UI} / \mathrm{mL}$ and $500 \mu \mathrm{g} / \mathrm{mL}$ of $\mathrm{P} / \mathrm{S}$ respectively. Fish were then immediately sacrificed by spinal dislocation. Head-kidney and spleen were aseptically removed, passed through a $100 \mu \mathrm{m}$ sterile nylon mesh and homogenised in $2 \mathrm{~mL}$ of L15 P/S containing heparin (10 UI/mL).

All samples were then separated into two equal parts. Leukocytes contained in the samples were then purified by two different methods as described as follow.

\subsection{Methods used for leukocytes isolation:}

\subsubsection{Density gradient:}

For each sample (head kidney, spleen or blood), $1 \mathrm{~mL}$ of cell suspension was diluted in $8 \mathrm{~mL}$ L15 P/S containing heparin (10 UI/mL) and layered onto $3 \mathrm{~mL}$ of Ficoll@ (density : 1.077 $\mathrm{g} / \mathrm{mL}$ ) and centrifuged at $400 \mathrm{~g}$ for 30 minutes at $4^{\circ} \mathrm{C}$. Leukocytes were collected at the culture medium-Ficoll@ interface and washed once in L15 P/S (centrifugation $400 \mathrm{~g}$ for 10 minutes at $4^{\circ} \mathrm{C}$ ). Supernatant was discarded and cells were resuspended in $1 \mathrm{~mL}$ of L15 P/S.

\subsubsection{Hypotonic lysis of erythrocytes:}

The protocol used was modified from Crippen et al. ( 2001). Nine mL of cold sterile distilled water was added to $1 \mathrm{~mL}$ of cell suspension. Tubes were mixed softly for 40 seconds in order 
153 (blood, spleen and head kidney). One mL of PBS 10X was immediately added to adjust the 154 sample osmolality. Suspensions were then centrifuged at $400 \mathrm{~g}$ for 10 minutes at $4{ }^{\circ} \mathrm{C}$.

155

156

157

158

159

160

For head-kidney samples, viscous pellet was removed,-supernatant was discarded and cell pellet restenspende $1 \mathrm{~mL}$ L15 penicillin/streptomycin with $5 \%$ of heat inactivated fetal calf serum was added. The viscous pellet with cells was gently pumped many times with a 5 $\mathrm{mL}$ pipet to release the most of cells. Then the viscous mass was discarded. For peripheral blood and spleen samples, viscous mass with cells was collected from the top of erythrocytes debris leucocytes pellets - and transferred into a new tube containing $1 \mathrm{~mL}$ L15 penicillin/streptomycin with $5 \%$ of heat inactivated fetal calf serum. Afterwards, cells were separated from the viscous pellet as done for head-kidney samples.Collectleukere diluted in $1 \mathrm{~mL} \mathrm{~L} 15 \mathrm{P} / \mathrm{S}$ containing $5 \%$ of heat inactivated fetal calf serum.

All the samples were analysed immediately after the leukocyte isolation procedure and also after a $12 \mathrm{~h}$ of incubation at $4^{\circ} \mathrm{C}$. After $12 \mathrm{~h}$ of incubation, cells were washed once by centrifugation $\left(400 \mathrm{~g}, 10\right.$ minutes at $\left.4{ }^{\circ} \mathrm{C}\right)$ and suspended in $1 \mathrm{~mL}$ of $\mathrm{L} 15 \mathrm{P} / \mathrm{S}$.

\subsection{Leukocytes parameters}

\subsubsection{Leukocytes distributions and concentrations:}

\subsubsection{Leukeytes distribution:}

Following isolation, all samples were diluted to $1: 10$ in phosphate buffer saline for cytogram examination and comparisen.

Representative cytograms obtained on leukocytes suspension isolated from head-kidney are represented in figure 1. Gate P1 was related to leukocytes (Figure 1 A and D). Gate P2 was done to exclude doublets by the use of FSC-H/FSC-A cytogram (Figures 1 B and E). Gate P3 was drawn to eliminate impurities as cell debris (Figures $1 \mathrm{C}$ and $\mathrm{F}$ ).

A total of 10000 events were recorded in P1 (Leukocytes) after exclusion of doublets. Data were analyzed with the Accuri ${ }^{\mathrm{TM}}$ C6 software. For leukocytes distributions, cell subtypes 
179 dotplots) (Figure 2.). For abbreviations of cell names, Ly corresponded to lymphocytes while 180 this gated subpopulation contained also thrombocytes [10,31,32].

181 After doublets exclusion (Figure 1; P2 gate), total events recorded in leukocytes gate (P1) 182 from $100 \mu \mathrm{L}$ of diluted tissue samples in PBS allowed to establish leukocyte concentration in 183 cell per $\mathrm{mL}$.

\subsubsection{Samples purity:}

185

186

The amount of sample purity was obtained by subtracting the percentage of events of the impurities gate (P3) from the whole analysed volume of sample (100\%) when events in leukocytes gate reached 10000 with doublets exclusion.

\subsection{Cellular functional tests:}

For each sample, $2 \times 10^{5}$ cell $/ \mathrm{mL}$ were deposited in $96-\mathrm{U}$ bottom wells microplates for functional cellular parameters analysis by flow cytometry. All cytometric measurements were carried out with an AccuriTM C6 flow cytometer (Becton Dickinson). For each leukocyte sample, 10,000 -vents were recorded and lencocytes were distingtished according to their morphologieal parameters, forward seatter (FSC- $A$ ) for particle size and side seatter (SSC-A) for internal complexity.

\subsubsection{Leukocytes mortality:}

Cell mortality was evaluated using propidium iodide (PI) probe at $1 \mu \mathrm{g} / \mathrm{mL}$. Analysis was carried by flow cytometry using $488 \mathrm{~nm}$ excitation laser and measuring fluorescence in associated channel through 585/15nm filter. Dead cells with injured membrane were positive to the red fluorescence-emitting probe bound to DNA. Results were expressed as mortality percentages corresponding to PI-positive cells (Fig.3. A and B). 
204 Leukocytes were incubated with yellow-green fluorescent latex beads (Fluoresbrite®,

205 Polyscience; $2 \mu \mathrm{m}$ diameter) for $18 \mathrm{~h}$ at $16^{\circ} \mathrm{C}$ with a $1 / 100$ leukocyte-beads ratio prior cytometric analysis measuring fluorescence in FL-1 channel (533/30) (Fig 4).

207

While adherence of foreign particles is the first step of the phagocytosis mechanism, the phagocytic activity measured corresponds to percentages of cells ingesting and/or adhering three beads and more. The mean number of ingested beads per phagocytic cells was calculated by dividing the mean fluorescence of events corresponding to three beads and more by the mean fluorescence of events corresponding to only one bead (Fig 4) [33].

\subsubsection{Oxidative activity assay:}

The leukocyte oxidative activity was quantified using flow cytometry to measure intracellular hydrogen peroxide production following activation or not with phorbol 12-myristate 13acetate (PMA). The fluorescence levels of DCFH was measured in unstimulated and PMAstimulated cells.were determined after 30 minof

Cells were incubated with 2'-7'dichlorofluorescin diacetate (DCFH-DA, 500nM, in obscurity at room temperature) for 15 minutes. Phorbol Myristate acetate (PMA, $2 \mu \mathrm{g} \cdot \mathrm{mL}^{-1}$ ) was then added or not (control) to cell suspensions and cells were incubated for 30 minutes in obscurity and at room temperature. Basal intracellular ROS production corresponds to the mean fluorescence of DCFH (in FL1) measured without any stimulation-in control whereas activated intracellular ROS production was the mean fluorescence of DCFH (in FL1) measured in cell after 30 minutes of incubation with PMA. For activated ROS production, the results were expressed in stimulation index as the ratio between the mean fluorescence measured in stimulated cells (DCFH-DA + PMA) and the basal mean fluorescence of control (DCFH-DA only) (Fig 5). 
229

230

231

232

233

Since data sets did not have a normal distribution and/or homogeneity of variance, all biological data were represented in boxplots with 25 th and 75 th percentiles over and below the median line within the box ( $\mathrm{N}=10$ different observations). Non-parametric Mann-Whitney $\mathrm{U}$ test was used to compare data obtained from each cell treatment $(p<0.05$ is considered statistically significant).

As all data were obtained on the same cell populations, correlations between leukocytes distributions and cell immune responses were calculated with the non-parametric Spearman correlations test. Values of correlation coefficients ( $\rho$ values) were significant at $p<0.05$. After Fisher's data transformation, differences between $\rho$ values obtained from different cell treatment (two different incubation times or two protocols for leukocyte isolation) were evaluated with Z-test of significance $(\mathrm{p}<0.05)$.

All data were statistically analysed with Statistica software (StatSoft, Inc. (2011). STATISTICA (data analysis software system, version 10. www.statsoft.com)).

\section{Results:}

\subsection{Leukocyte cytograms profiles:}

Cytograms of isolated leukocytes show that Head-kidney profiles show the highest celt contents and were then used to gate dot plots and delimit sub-populations areas on cytograms (Fig.1 D). three leucocytes sub populations (lymphocytes, monøcytes/macrophages, granulocytes) and especially granulocytes were more visible on cytograms of cell suspensions obtained by hypotonic lysis (HL) in comparison with cytograms of leukocytes isolated by density gradient centrifugation on both times of analysis (no incubation and after 12 hours of incubation) (Fig 6) (Fig.1). Head-kidney isolated leukocytes denoted also higher content of granulocytes. This observation was also valid for spleen and blood leukocytes cytograms (Fig. 1). 
254

255

256

257

258

259

260

261

262

263

264

265

266

267

268

269

270

271

272

273

274

275

276

\subsection{Leucocytes concentrations:}

In this study, each sample was treated for leukocytes collection using the two methods simultaneously and side by side. The median of yield obtained from 10 fish organs does not reflect the average leukocytes number in a whole collected organ (Table1).

Head-kidney leukocytes concentrations obtained with HL protocol is visually higher than cell concentrations provided after density gradient centrifugation of cells $\left(14 \times 10^{6}\right.$ cell/mL for HL than $8.93 \times 10^{6}$ cell $/ \mathrm{mL}$ for DG) (Table 1). However, no significant difference appears between these two methods as the min-max values were in the same range (DG: $\left[4.69 \times 10^{6}-20.4 \times 10^{6}\right.$ ] and HL: $\left.\left[7.83 \times 10^{6}-24.1 \times 10^{6}\right]\right)$ (Table 1$)$. This high variability in results may explain this non-statistical difference despite of difference observed for median cell concentrations obtained. For the two other tissues (blood and spleen), no statistical difference was observed for median leukocytes concentrations between the two protocols used (Table 1).

\subsection{Comparison of samples purity between isolation methods:}

Cytograms were also exploited as tool for evaluation of samples purity following isolation. Small debris at the origin of cytograms axis were excluded. Leukocytes dots and thrombocytes were gated together and the rest was assigned as impurities: debris and cell ghosts. Thrombocytes were included in measurements as there are indistinguishable from lymphocytes. methods resulted in their collection with leukocytes. It is important to note that for leukøcyte distribution measurements, thrombocytes are not included in analysis. Only lymphøcytes, monocytes/macrophages and granulocytes are taken into account.

Cell isolation by DG led to significant higher purity levels in leukocytes for obtained cell suspension in comparison with cell suspensions where leukocytes were isolated by HL (Table 2). This observation was valuable for the three tissues used (spleen: $p=0.0051$; head-kidney: 
278 with DG and $89.2 \%$ with HL protocols) (Table 2).

279

280

281

282

283

284

285

286

287

288

289

290

291

292

293

294

295

296

297

298

299

300

301

\subsection{Leukocytes sub-populations distributions:}

HL protocol was associated with cell suspensions containing more granulocytes than those obtained after DG protocol whatever the post-isolation incubation time used (Fig. 7). The greater difference was observed for head-kidney isolated leukocytes particularly when leukocytes suspension were incubated for $12 \mathrm{~h}$ after isolation $(p=0.00007$ for lymphocytes, $p=0.023$ for monocytes/macrophages and $p=0.00002$ for granulocytes) (Fig. 7). For cell isolated from spleen, the most notable difference between the two protocols were observed for leukocytes distributions evaluated immediately after isolating procedure $(p=0.0004$ for lymphocytes, $p=0.023$ for monocytes/macrophages, $p=0.0038$ for granulocytes) (Fig. 3). After $12 \mathrm{~h}$ of incubation, only percentages of granulocytes were significantly higher in cell suspensions obtained after HL than those obtained after DG ( $p=0.00001$ for granulocytes) (Fig. 7). The HL method also brought significant difference in blood tissue with more collected lymphocytes and granulocytes especially after purification $(p=0.011$ for lymphocytes and $p=0.014$ for granulocytes) and with more collected granulocytes after $12 \mathrm{~h}$ of cell incubation $(p=0.022)$ (Fig. 7).

It is important to note that density gradient in terms of leukocytes distribution has more stability. In fact, leukocytes show near percentage of composition right after isolation or after 12h incubation in all organs with slightly more stability in spleen (No incubation : lymphocytes $82.34 \%$; monocytes/macrophages: $13.14 \%$; granulocytes: $2.24 \%$ - 12 hours of incubation: lymphocytes 87.09\%; monocytes/macrophages: 11.91\%; granulocytes: $0.92 \%$ ) than head-kidney (No incubation : lymphocytes 65.29\%; monocytes/macrophages: 12.33\%; granulocytes: $19.58 \%$ - 12 hours of incubation: lymphocytes $52.73 \%$; monocytes/macrophages: 15.54\%; granulocytes: 26.58\%) or blood (No incubation : 
lymphocytes $76.42 \%$; monocytes: $17.72 \%$; granulocytes: $3.83 \%$ ).

304

305

306

307

308

309

310

311

312

313

314

\subsection{Leukocytes mortality:}

For splenocytes, a significant greater variability on cells mortality rates is noticeable immediately after cell isolation, for total leukocyte populations when using HL compared to DG protocol (DG: 3.08\%; HL: 8.71\%; $p=0.035$ ) (Fig.8.A). Nevertheless, amounts of mortality are in the same range for total leukocytes and the various subtypes after $12 \mathrm{~h}$ of cell incubation. Mortality measured in total head kidney-isolated leukocytes immediately after their isolation was significantly higher after DG than after HL protocol $(3.99 \%$ and $2.64 \%$ respectively; $p=0.018$ ) (Fig.8.B). Any-No other difference was observed for head-kidney cells. Freshly isolated blood leukocytes had significant high mortality with HL compared to DG $(4.81 \%$ and $1.36 \% ; p=0.002)$. This cell death concerned lymphocytes sub-types $(0.59 \%$ for $\mathrm{DG}$ and $1.87 \%$ for $\mathrm{HL} ; \quad p=0.043$ ) (Fig.8.C). A higher variability in monocytes/macrophages mortality was observed following the isolating protocol (Fig.8.C). AnyNo other differences in cell mortality appeared after $12 \mathrm{~h}$ of cell incubation in all cell types.

\subsection{Basal oxidative activity:}

Just after the cell isolation phase, splenocytes (particularly lymphocytes and monocytes/macrophages), isolated with DG had significant higher basal ROS production in comparison with cell isolated by HL method ( $p=0.0003$ and $p=0.0002$ respectively) (Fig. $5 \mathrm{~A})$. After $12 \mathrm{~h}$ of post-isolation incubation, there were-were noany more-differences in basal oxidative activity between the two cell isolating procedures (Fig.9.A).We noticed that basal oxidative activity tends to be greater for granulocytes compared to the two other cell types. Whatever procedure used to isolate head kidney leukocytes, their basal ROS production did not differ between the different cell populations immediately after cell isolation and also after 
oxidative activity of head-kidney leukocytes just after their isolation by DG (Fig.9.B). After

$33012 \mathrm{~h}$ of incubation, this variability in basal ROS production disappeared for head kidney cells

331 isolated by DG and appeared with head kidney cells isolated by HL. All blood leukocytes

332 subtypes incubated for $12 \mathrm{~h}$ after isolating procedure had higher basal oxidative activity when

333 they were isolated by the use of DG in comparison with same cell types isolated by HL

334 ( $p=0.00008$ for lymphocytes, $p=0.00008$ for monocytes/macrophages, $p=0.011$ for

335 granulocytes) (Fig.9.C).

\subsection{PMA-stimulated oxidative activity:}

337

Granulocytes of DG-purified spleen leukocytes show higher SI comparatively to HL-purified ones after purification but with no statistically significant difference (Stimulation index 31.26 and 19.90 respectively) (Table 3). A statistical difference belongs to spleen lymphocytes where after $12 \mathrm{~h}$ of incubation, DG isolated lymphocytes have significant higher PMAstimulated oxidative activity compared to their counterparts isolated by HL (Stimulation index 6.80 and 2.88 respectively, $p=0.0354$ ) (Table 3). Isolated head-kidney leukocytes highlighted the highest PMA-induced oxidative activity. This observation concerns essentially HL-isolated cells but no significant statistical difference was observed between isolation methods (Table 3). After $12 \mathrm{~h}$ of incubation, stimulation index indicating the PMA-induced oxidative activity in leukocytes were low for all cell types. In a general way, PMA-induced oxidative activity measured in blood leukocytes was in a same order of magnitude for the two cell isolation mode. The only difference was observed for DG-isolated lymphocytes which had higher PMA-induced oxidative activity after $12 \mathrm{~h}$ incubation in comparison with HLisolated lymphocytes (Stimulation index: 2.90 and 1.40 respectively, $p=0.0464$ ) (Table 3).

\subsection{Phagocytosis:}

It is important to mention here that the analysis of phagocytosis by flow cytometry doesn't allow to discriminate this cell activity at the cell subtype scale. The latex microsphere 
granularity).

356

357

358

359

360

361

362

363

364

365

Head-kidney leukocytes purified with DG had higher phagocytic activities than the same cells isolated by HL (66.35\% and $42.44 \%$ respectively, $p=0.0432)$. This observation was only valid when cell activities were taken as a result of cell isolation with no incubation (Table 4).

Only leukocytes of head-kidney show less score with HL (7.41 compared to DG method (8.76) with statistical significant difference $(p=0.0089)$ (Table 5).

The mean numbers of ingested beads per phagocytic cells were not modulated neither by the cell isolation protocol nor by the post-isolation incubation time (Table 5). One can simply signal a tendency to a slightly higher number of beads in cells after $12 \mathrm{~h}$ incubation following their isolation compared to values observed when phagocytosis was observed immediately after cell isolation (no incubation) (Table 5).

\subsection{Purification methods, leukocytes distribution and immune responses:}

For DG-isolated leukocytes from spleen, granulocytes percentages were positively correlated with PMA-induced oxidative activity in granulocytes immediately after cell isolation $(0.663)$ (Table 6). For HL-isolated splenocytes, significant positive correlation were observed between granulocytes levels and PMA-induced oxidative activity for the three leukocytes subtypes just after their isolation from spleen (Table 6). If the cell were not incubated at $4^{\circ} \mathrm{C}$ after their isolation by HL, granulocytes percentages were significantly and positively correlated with phagocytic activities of leukocytes in samples (phagocytosis activity 0.697, number of ingested beads 0.806) (Table 6). After $12 \mathrm{~h}$ of incubation of spleen-isolated leukocytes by DG, positive correlations were observed between lymphocytes percentages and their PMA-stimulated oxidative activity (0.685). After the same treatment, monocytes/macrophages levels in spleen were positively correlated with basal oxidative activities of all leukocytes subtypes (Table 6). After $12 \mathrm{~h}$ of incubation of spleen-isolated cells by HL, levels in monocytes/macrophages and also in granulocytes were positively correlated 
381 beads) (0.806 and 0.867 respectively) (Table 6). Such correlations were not observed in

382 leukocytes suspensions obtained after cell isolation with DG $(p=0.0118$ and 0.0068 respectively for the two phagocytic immune endpoints) (Table 6).

In head-kidney, lymphocytes levels obtained by the use HL method show positive correlation with all the basal oxidative activities measured separately in each leukocytes subtypes after $12 \mathrm{~h}$ of cell incubation at $4^{\circ} \mathrm{C}$ (lymphocytes: 0.782, monocytes/macrophages: 0.818 , granulocytes: 0.806) (Table 6). This result was not observed for DG-isolated leucocytes with significant differences between the two protocols used. ( $p=0.044,0.0174$ and 0.0320 respectively) (Table 6). In blood tissue, lymphocytes percentages have positive correlations with PMA-induced oxidative activity in the three leukocytes subtypes after $12 \mathrm{~h}$ of incubation of cell suspension at $4^{\circ} \mathrm{C}$ using DG method (lymphocytes: 0.767 , monocytes/macrophages: 0.900, granulocytes: 0.817) (Table 6). Such observation was not found in blood-isolated cells with HL protocol used.

\section{Discussion:}

The objective of our study was to investigate the effects of two cell isolation techniques on cellular responses measured to assess the immune endpoints related to the evaluation of immune status of fish, in different experimental contexts (ex vivo, in vivo, in situ). Our observations were realized from three biological compartments classically studied in fish immunology: spleen, head kidney and blood. The thymus, which is important in the immune response of fish, has not been taken into account in our study because of our lack of knowledge of its anatomical location in roach and also of relative low quantities of leucocytes that can be isolated from this organ in two-year-old fish such as those used in our study [34].

One of the difficulties of these analyses lies in the necessity of carrying out measurements on suspensions of live leucocytes extracted from the lymphoid tissues. Teleost fish have the particularity to possess nucleated erythrocytes. These cells are naturally present in the various 
407

408

409

410

their very large quantities in tissues, disrupt the analyses of leukocyte functionality whatever the techniques used (microscopy, flow cytometry, etc.). It is therefore essential to eliminate erythrocytes from leucocyte suspensions in order to acquire leukocyte response data as close as possible to the functional realities of these cells within the studied organism.

Two leukocyte isolation methods based on the elimination of erythrocytes were studied here, one classically corresponding to a density gradient obtained by centrifugation and a second to date less used and corresponding to a hypotonic lysis of red blood cells [23]. Initially, these methods essentially target the blood compartment. Blood is indeed the obvious tissue to be sampled for leukocyte collection and for which the inconvenience of erythrocyte contamination in leukocyte suspensions is the most important. But interests about the immune responses in spleen and anterior kidney led us to submit them to these same two protocols in order to extract their leukocyte cells.

Obtaining leucocyte suspensions requires several crucial and unavoidable phases [35]. First of all, the tissue must be taken from the whole organism. For the blood, its sampling requires the use of a syringe containing an anticoagulant and allowing for the fish of sufficient size (> 10 $\mathrm{cm})$, the non-invasive blood sampling notably in the caudal vein of the fish [36,37]. For headkidney and spleen, samples are taken by the organ dissection corresponding to its extraction from the abdominal cavity of the fish. The organ is then dilacerated, mechanically crush in culture medium through a nylon mesh filter $(100 \mu \mathrm{m})[33,36]$. Blood samples or crushed organs are then processed to remove tissue debris and non-leukocyte cells. In case of separations using centrifugation gradients, the samples are deposited as in our study, on a Ficoll@ solution (commercial name of a liquid polyfluorocarbon solution with $1.077 \mathrm{~g} / \mathrm{mL}$ density) and centrifuged for several minutes. Used speeds and centrifugation times lead to a differential separation of leukocytic cells according to their densities. The red blood cells and debris are found at the bottom of the centrifuge tube and leukocytes are concentrated in a ring shape on Ficoll@ surface. After leukocytes recovery, it is necessary to wash them in an excess 
434 toxic to the cells [38]. A new centrifugation leading to a cell sedimentation in tube bottom

435 allows to eliminate supernatant containing Ficoll@-contaminated culture medium.

436

437

438

439

440

441

442

443

444

Regarding leukocyte separations based on the removal of erythrocytes by osmotic lysis, the best known methods are used in mammals to remove red blood cells by hyperosmotic shock using ammonium chloride. Such lysis is not valid in teleost due to the nuclei presence in fish erythrocytes which prevent lysis [35]. In 2001, Crippen and colleagues described a technique for removing erythrocytes in trout blood and head-kidney samples by changes in their surrounding environment isotonicity. It is this protocol that we used here with some adaptations for the roach species. Thus, blood samples or crushed organs obtained from the sampling phase were rapidly and transiently exposed to hypotonic conditions (addition of sterile distilled water for 40 seconds). After a rapid isotonicity restoration of medium, cells were centrifuged in order to remove debris allowing cell pellets to be taken up in culture medium. Note that some leukocyte isolation protocols associate osmotic lysis with centrifugation gradient [39]. In our case, these two methods were used separately.

These various steps may constitute physical and chemical stresses for the cells. The question is what are the possible consequences of such stress on the functional analyzes carried out on these cells? In order to limit it, it seems advisable not to do the analyzes immediately after the leukocyte isolation and to subject cell suspensions to a "rest" phase in order to allow them to "recover" from possible traumas created by all the successive phases of the protocols (sampling, crushing, centrifugation, etc.). Therefore, in our study, for the purposes of comparisons, the analyzes were carried out either directly on the freshly isolated leukocytes or on cells incubated for $12 \mathrm{~h}$ at low temperature $\left(+4^{\circ} \mathrm{C}\right)$ after the isolating procedure.

In fish, if leukocyte distribution data may vary from one species to another and inside the same species, this endpoint is also modulated by the development stage of the organism but also naturally according to its parasitic status $[9,40]$. 
follow: lymphocytes $(1.020 \mathrm{~g} / \mathrm{mL})$, monocytes / macrophages $(1.070 \mathrm{~g} / \mathrm{mL})$ and granulocytes

461

462

463

464

465

466

467

468

469

470

471

472

473

474

475

476

477

$(1.083 \mathrm{~g} / \mathrm{mL})$ [41]. The Ficoll@ density being $1.077 \mathrm{~g} / \mathrm{mL}$, it is then understandable that leukocyte isolation, based on the use of a Ficoll® gradient, leads to the isolation of lymphocytes and monocytes / macrophages cell types [42]. That's confirmed by our results. Compared to the density gradient, hypotonic lysis is associated with leukocyte enrichments, which essentially concern granulocytes for the three tissues targeted in our study. This result is particularly noticeable for leukocyte suspensions isolated from head kidney where granulocytes are naturally abundant [16]. However, the head kidney is also a tissue where there is a production of lymphocytes, particularly B lymphocytes $[43,44]$. More recently, the use of marked antibodies specific for certain cell types, has shown that density gradients alone can influence the leukocyte composition of blood compared to data acquired on whole blood [45].

The higher collection of lymphocytes obtained with DG method may trigger shifts in cells reaction as our results show correlation between lymphocytes amounts and oxidative activity in the whole cells suspensions in blood and head-kidney noticeable after a period of cells incubation (Table 6). In spleen, this phenomenon is observable with monocyte/macrophages cells. As a matter of fact, Ulmer et al. (1984) showed a density modulation of mammalian monocytes using Ficoll® separation that grants them same density as lymphocytes, a difficulty in defining leucocytes sub-populations when using flow cytometry. After $12 \mathrm{~h}$ of post-isolation incubation, differences disappear which confirm our advice on the use of cell incubation before their cytometric analysis.

The granulocyte enrichment of leukocytes suspensions after HL isolation method was confirmed by positive correlations on granulocytes amounts in head-kidney samples and the related high phagocytic activity of leukocytes. This increase in phagocytosis in cell suspensions obtained after leukocyte isolation by HL could be explained by increase of cell debris in cell suspensions by the use of this technique. Therefore, Zhou et al. (2012) stress out 
purification method.

488

489

490

491

492

493

494

495

496

497

498

499

500

501

502

503

504

505

506

507

508

509

510

511

Data of leukocytes distributions in lymphoid tissues depend very much on the leukocyte isolation modalities (Table 7).

Our leukocyte distribution data and those obtained in literature are clearly modulated by the choice of the leukocyte isolation protocol (especially for spleen and head-kidney leukocytes) (Table 7).

However, such influence was not observed for isolated trout leukocytes using protocols that were relatively similar to those used in our study [23] (Table 7). Whether acquired by Percoll@ discontinuous density gradients or by histopaque-1077 density gradients or by the use of hypotonic lysis, leukocyte compositions are found to be similar in rainbow trout (Oncorhynchus mykiss) whatever the isolating protocol used [23] (Table 7). Such a result is surprising insofar as the two types of gradient used by these authors and similar to ours, allow to isolate the mononucleated cells, namely lymphocytes and monocytes / macrophages.

An important variability is observed in leucocyte distributions between the two incubation conditions (no incubation or $12 \mathrm{~h}$ of incubation at $4{ }^{\circ} \mathrm{C}$.) to which the cells are subjected after their isolation by hypotonic lysis. This variability in cell types' proportions was observed for the spleen and head kidney leukocyte suspensions. It could be due to the cell heterogeneity in these two organs and to the various sensitivities of cells which constitute them to the osmotic stress undergone during the isolation phase. Indeed, studies show that leukocyte sensitivity to osmotic stress results in oxidative stress altering their long-term survival [60]. It should be noted that in our study, hypotonic lysis as well as density gradient, has no significant effect on leucocyte mortality, regardless of the tissue from which these leukocytes are derived. However, it can be noted that method to estimate cell mortality we used (labeling cell with propidium iodide) only takes into account the cell deaths by necrosis and not those due to apoptosis. Thus, the variability observed over time in leucocyte distributions of cell isolated 
513 destabilizations in certain leukocyte categories such as lymphocytes. However, as head-

514 kidney is considered as a leukopoietic organ with more granulocytes content and naïve cells

515 than spleen or blood, a cell proliferation may be possible explaining difference observed

516 during incubation time. We can noticed that the use of Ficoll@ gradient was associated with a

517 better stability in cellular distributions observed between the two incubation times.

518 The studies using continuous density gradients (with Ficoll@ or Percoll@: densities 1.077 and

$5191.075 \mathrm{~g} / \mathrm{mL}$ respectively) are relatively numerous $[9,10,22,61]$. The relative small amounts

520 of granulocytes recovered by this type of leukocyte isolation may limit observations on

521 lymphocytes-related functions, such as the adaptive response of antibody production [62,63].

522 Thus, the use of hypotonic lysis must lead to a better vision of the overall fish immune

523 response, taking into account, besides adaptive immunity, of natural immunity with a best

524 isolation of granulocyte cells $[64,65]$. In addition, taking into account the different leucocyte

525 subpopulations is very important as the tissue leukocyte distribution (particularly blood)

526 constitutes a strong marker of stressed organism in vertebrates [66]. The lymphocyte /

527 granulocyte ratio favorable to lymphocytes in the normal body is modified in favor of 528 granulocytes when the fish are stressed [57,67].

529 Since the two protocols used in our study led to differences in leucocyte distributions for the 530 three studied tissues, implications in responses of studied immune functions were expected.

531 The effects of the two modes of cell isolation were observed on two major functions of the

532 native fish immunity, phagocytosis and basal/stimulated leukocyte oxidative activities. The

533 effects on cell mortality were analyzed as this data is important for interpretation of cellular

534 functional responses. The two treatments did not induce significant mortality, the most

535 notable effects appearing for the cells which have just been isolated. Therefore, the cell

536 incubation for 12 hours at $4^{\circ} \mathrm{C}$ may reduce the potential deleterious effects of the isolating 537 procedures. 
539

540

541

542

543

544

545

oxidative activity which disappears after $12 \mathrm{~h}$ of cell incubation at $+4^{\circ} \mathrm{C}$. This increase essentially concerns splenocytes. The blood leukocytes isolated by this same method exhibit high basal oxidative activities after $12 \mathrm{~h}$ of incubation at $4^{\circ} \mathrm{C}$ and for the three leukocyte types (lymphocytes, monocytes and granulocytes). When leukocytes are exposed to PMA for stimulation of intracellular ROS production, head kidney cells isolated by hypotonic lysis show the highest stimulation levels. This stimulation disappears after $12 \mathrm{~h}$ of cell incubation at $+4^{\circ} \mathrm{C}$. A same phenomenon is observed for blood leukocytes isolated by hypotonic lysis but only immediately after the isolation phase.

Thus, such observations reveal that density gradient isolation leads to a transitory increase in basal ROS production in spleen lymphocytes whereas hypotonic lysis is associated with an increase in PMA-induced ROS production especially in head kidney leukocytes.

These increases in cell oxidative activities, particularly those induced by PMA, are consistent with increases in granulocyte proportions observed in leukocyte suspensions obtained by hypotonic lysis. Expectedly, granulocytes are the cells that exhibit the highest oxidative activities in comparison with other cell types. This observation is consistent with the functional capacities of these cells, which play an important role in inflammatory process $[68,69]$. The stronger stimulation in PMA-induced oxidative activity observed in head kidney leukocytes was not due to a cell priming induced by the isolation protocol but to the increase in granulocytes amounts in the Leucocyte suspensions obtained.

If effects are observed on cellular oxidative activities, no effect appears on phagocytosis. A low tendency of decrease is observed for leukocytes isolated by hypotonic lysis. Such a result is surprising given the increased presence of granulocytes in leukocyte suspensions obtained by hypotonic lysis. Although macrophages are important phagocytic cells, granulocytes have an intense phagocytosis activity in numerous fish species [70,71]. The persistence in phagocytosis activity of cells isolated by erythrocytes hypotonic lysis and its non-stimulation 
565 this cell function by conditions linked to the leukocyte isolation procedure used. In our study,

566 the hypotonic lysis protocol used consists in a rapid cell exposure to cold distilled water. Cell

567 exposition to such conditions could explain the inhibition in cellular phagocytosis activity.

568 Another explanation could be related to the fish species studied. In roach, phagocytosis could

569 be carried out by myeloid cells (monocytes/macrophages and granulocytes) but also by B

570 lymphocytes [72,73]. Since the two isolation protocols used have a limited influence on the

571 lymphocyte levels in cell suspensions, this leads to a relative stability in phagocytosis activity

572 whatever the isolation treatment of cells.

573 Whatever the isolation method used, our results show their effects on intracellular ROS

574 production. These oxidative activations sometimes only concern some leukocyte types (spleen

575 lymphocytes and monocytes/macrophages) or in other cases all populations (particularly

576 blood leukocytes) are concerned. For this last point, hypotonic lysis leads to a transient

577 increase in PMA-stimulated oxidative activity of head kidney leukocytes whereas isolation by

578 density gradient increases the oxidative activity of blood leucocytes. It is important to note

579 that our results had some limitations concerning for instance the relative few numbers of

580 observations $(\mathrm{N}=10)$ which may depend also on the physiological status of fish used (2 years

581 old fish, in reproduction phase of their biological cycle and with no apparent parasitism).

582 Within limits of our experimental conditions, the spleen is the organ whose leucocyte oxidative activities (stimulated or not) are only slightly influenced by the methods used for leukocyte isolation. This is also the case for the anterior kidney, but for this tissue, it is necessary to incubate the isolated cells for $12 \mathrm{~h}$ at $+4^{\circ} \mathrm{C}$.

Thus, our study improves knowledge about the effects of two protocols used for leukocyte isolation on cell functions very commonly analyzed in fish immunology. In the balance sheet, each of the two methodologies used has advantages and disadvantages. The hypotonic lysis

589 allows to isolate a greater variety of leukocytes types whereas the density gradient used 
591 recovery of cells following their isolation (for instance $12 \mathrm{~h}$ at $+4^{\circ} \mathrm{C}$. as in our study) is

592 required in order to improve quality of obtained results.

593 To date, studies in which the hypotonic lysis protocol has been used are few. Data on its

594 effects on cell functions are still limited and further works should be carried out to better

595 understand the impact of this type of leukocyte isolation procedure depending on targeted fish 596 species.

597 It is important to note out that results in leukocyte separation in terms of quantities and 598 qualities of isolated cell types are influenced by all the different steps required for cell 599 isolation. For the same fish species and for the same tissue, Ficoll® use may be associated 600 with different centrifugation times and rates leading to differences in leukocytes distributions 601 obtained [35] (Table 7). Thus, it is the set of two protocols used which may influence results 602 and which must be taken into consideration during acquired data analysis. Other protocols for 603 leukocyte isolation exist and our study does not pretend to be complete on this subject.

604

605

606

607

608

609

610

611

612

Among the selection criteria for leukocyte isolation protocols, logistical constraints associated with experiments must also be taken into account. Sometimes, this is the case in studies carried out in eco-immunology and eco-physiology on fish species of wild fauna. Some tradeoffs must be done between technical feasibility of experiments which should not be too long in order to ensure the optimum conservation of living cell samples and the statistical requirements in terms of quantity of observations required to ensure validity of results.

Acknowledgements: This work was supported by the Nationale Institute of Industrial Environment and Risks (Verneuil-en-Halatte, France) and by the University of Reims (Reims Métropole funding, France).

\section{References:} operate with confused terms?, J. Avian Biol. 42 (2011) 490-493. doi:10.1111/j.1600- 
617

618

619

620

621

622

623

624

625

626

627

628

629

630

631

632

633

634

635

636

637

638

639

[2] A.E. Ellis, Innate host defense mechanisms of fish against viruses and bacteria., Dev. Comp. Immunol. 25 (2001) 827-39. doi:10.1016/S0145-305X(01)00038-6.

[3] A.E. Ellis, Immunity to bacteria in fish, Fish Shellfish Immunol. 9 (1999) 291-308. doi:10.1006/fsim.1998.0192.

[4] B. Magnadóttir, Innate immunity of fish (overview), Fish Shellfish Immunol. 20 (2006) 137-151. doi:10.1016/j.fsi.2004.09.006.

[5] M.B. John, M.R. Chandran, B. V Aruna, K. Anbarasu, Production of superoxide anion by head-kidney leucocytes of Indian major carps immunised with bacterins of Aeromonas hydrophila, Fish Shellfish Immunol. 12 (2002) 201-207. doi:10.1006/fsim.2001.0365.

[6] S.K. Whyte, The innate immune response of finfish - A review of current knowledge, Fish Shellfish Immunol. 23 (2007) 1127-1151. doi:10.1016/j.fsi.2007.06.005.

[7] C.K. Misra, B.K. Das, S.C. Mukherjee, P.K. Meher, The immunomodulatory effects of tuftsin on the non-specific immune system of Indian Major carp, Labeo rohita, Fish Shellfish Immunol. 20 (2006) 728-738. doi:10.1016/j.fsi.2005.09.004.

[8] V.I. Lushchak, Environmentally induced oxidative stress in aquatic animals., Aquat. Toxicol. 101 (2011) 13-30. doi:10.1016/j.aquatox.2010.10.006.

[9] S. Chilmonczyk, D. Monge, Flow cytometry as a tool for assessment of the fish cellular immune response to pathogens, Fish Shellfish Immunol. 9 (1999) 319-333. doi:10.1006/fsim.1998.0188.

[10] T. Inoue, T. Moritomo, Y. Tamura, S. Mamiya, H. Fujino, T. Nakanishi, A new method for fish leucocyte counting and partial differentiation by flow cytometry., Fish Shellfish Immunol. 13 (2002) 379-390. doi:10.1006/fsim.2002.0413. 
641

642

643

644

645

646

647

648

649

650

651

652

653

654

655

656

657

658

659

660

661

662

663

664

cytometry detection of lysosomal presence and lysosomal membrane integrity in the three-spined stickleback (Gasterosteus aculeatus L.) immune cells: applications in environmental aquatic immunotoxicology., Environ. Sci. Pollut. Res. Int. 20 (2013) 2692-704. doi:10.1007/s11356-012-1410-2.

[12] B. Gagnaire, A. Bado-Nilles, W. Sanchez, Depleted Uranium Disturbs Immune Parameters in Zebrafish, Danio rerio: An Ex Vivo/In Vivo Experiment, Arch. Environ. Contam. Toxicol. 67 (2014) 426-435. doi:10.1007/s00244-014-0022-x.

[13] G.T. Haugland, A. Rønneseth, H.I. Wergeland, Flow cytometry analyses of phagocytic and respiratory burst activities and cytochemical characterization of leucocytes isolated from wrasse (Labrus bergylta A.)., Fish Shellfish Immunol. 39 (2014) 51-60. doi:10.1016/j.fsi.2014.04.023.

[14] F. Souques, C. Duperray, J. Pène, J. Bousquet, B. Arnoux, Modification of surface marker expression on CD14 monocytes of allergic patients after lysis or Ficoll purification, J. Immunol. Methods. 204 (1997) 153-160. doi:10.1016/S00221759(97)00039-2.

[15] L. Zhou, R. Somasundaram, R.F. Nederhof, G. Dijkstra, K.N. Faber, M.P. Peppelenbosch, G.M. Fuhler, Impact of human granulocyte and monocyte isolation procedures on functional studies, Clin. Vaccine Immunol. 19 (2012) 1065-1074. doi:10.1128/CVI.05715-11.

[16] J.L. Congleton, A.R. Greenlee, S.S. Ristow, Isolation of leucocytes from the anterior kidney and spleen of rainbow trout in a self-generating density gradient, J. Fish Biol. 36 (1990) 575-585. doi:10.1111/j.1095-8649.1990.tb03558.x.

[17] T. Mosca, W.C.N. Forte, Comparative Efficiency and Impact on the Activity of Blood Neutrophils Isolated by Percoll, Ficoll and Spontaneous Sedimentation Methods, 
666

667

668

669

670

671

672

673

674

675

676

677

678

679

680

681

682

683

684

685

686

687

688

[18] M.I. Concha, V.J. Smith, K. Castro, A. Bastías, A. Romero, R.J. Amthauer, Apolipoproteins A-I and A-II are potentially important effectors of innate immunity in the teleost fish Cyprinus carpio, Eur. J. Biochem. 271 (2004) 2984-2990. doi:10.1111/j.1432-1033.2004.04228.x.

[19] C. Findlay, M.F. Tatner, A comparative study of T and B lymphocytes in rainbow trout (Oncorhynchus mykiss) following their separation by nylon wool adherence and lectin agglutination techniques, Comp. Haematol. Int. 4 (1994) 55-60. doi:10.1007/BF00368268.

[20] M.C. Tellez-Bañuelos, P.C. Ortiz-Lazareno, A. Santerre, J. Casas-Solis, A. BravoCuellar, G. Zaitseva, Effects of low concentration of endosulfan on proliferation, ERK1/2 pathway, apoptosis and senescence in Nile tilapia (Oreochromis niloticus) splenocytes, Fish Shellfish Immunol. 31 (2011) 1291-1296. doi:10.1016/j.fsi.2011.10.003.

[21] J.D. Ogle, C.K. Ogle, J. Greg Noel, P. Hurtubise, J. Wesley Alexander, Studies on the binding of C3b-coated microspheres to human neutrophils, J. Immunol. Methods. 76 (1985) 47-62. doi:10.1016/0022-1759(85)90480-6.

[22] G. Mainwaring, A.F. Rowley, Separation of leucocytes in the dogfish (Scyliorhinus canicula) using density gradient centrifugation and differential adhesion to glass coverslips, Cell Tissue Res. 241 (1985) 283-290. doi:10.1007/BF00217172.

[23] T.L. Crippen, L.M. Bootland, J.A.C. Leong, M.S. Fitzpatrick, C.B. Schreck, A.T. Vella, Analysis of salmonid leukocytes purified by hypotonic lysis of erythrocytes, J. Aquat. Anim. Health. 13 (2001) 234-245. doi:10.1577/1548-

8667(2001)013<0234:AOSLPB>2.0.CO;2. 
691

692

693

694

695

696

697

698

699

700

701

702

703

704

705

706

707

708

709

710

salmon (Oncorhynchus tshawytscha) using flow cytometry, Fish Shellfish Immunol. 15 (2003) 145-158. doi:10.1016/S1050-4648(02)00151-1.

[25] K. Burt, D. Hamoutene, J. Perez-Casanova, A. Kurt Gamperl, H. Volkoff, The effect of intermittent hypoxia on growth, appetite and some aspects of the immune response of Atlantic salmon (Salmo salar), Aquac. Res. 45 (2013) 124-137. doi:10.1111/j.13652109.2012.03211.x.

[26] M. Makesh, P.S. Sudheesh, K.D. Cain, Systemic and mucosal immune response of rainbow trout to immunization with an attenuated Flavobacterium psychrophilum vaccine strain by different routes, Fish Shellfish Immunol. 44 (2015) 156-163. doi:10.1016/j.fsi.2015.02.003.

[27] D. Hamoutene, J.F. Payne, H. Volkoff, Effects of tebufenozide on some aspects of lake trout (Salvelinus namaycush) immune response, Ecotoxicol. Environ. Saf. 69 (2008) 173-179. doi:10.1016/j.ecoenv.2007.04.012.

[28] M. Ferraris, S. Radice, P. Catalani, M. Francolini, L. Marabini, E. Chiesara, Early oxidative damage in primary cultured trout hepatocytes: a time course study, Aquat. Toxicol. 59 (2002) 283-296. doi:10.1016/S0166-445X(02)00007-3.

[29] R. Dulbecco, M. Vogt, Plaqueq formation and isolation of pure lines with Poliomyelitis viruses*, J. Exp. Med. 99 (1954) 167-182. doi:10.1084/jem.99.2.167.

[30] P. Geraudie, M. Gerbron, E. Hill, C. Minier, Roach (Rutilus rutilus) reproductive cycle: A study of biochemical and histological parameters in a low contaminated site, Fish Physiol. Biochem. 36 (2010) 767-777. doi:10.1007/s10695-009-9351-5.

[31] M. Pierrard, K. Roland, P. Kestemont, M. Dieu, M. Raes, F. Silvestre, Fish peripheral blood mononuclear cells preparation for future monitoring applications, Anal.

Biochem. 426 (2012) 153-165. doi:10.1016/j.ab.2012.04.009. 
715

[32] T. Moritomo, A. Minami, Y Inoue, T. Nakanishi, A new method for counting of quail leukocytes by flow cytometry., J. Vet. Med. Sci. 64 (2002) 1149-1151. doi:10.1292/jvms.64.1149.

[33] S. Jolly, A. Jaffal, L. Delahaut, O. Palluel, J.M. Porcher, A. Geffard, W. Sanchez, S. Betoulle, Effects of aluminium and bacterial lipopolysaccharide on oxidative stress and immune parameters in roach, Rutilus rutilus L., Environ. Sci. Pollut. Res. 21 (2014) 13103-13117. doi:10.1007/s11356-014-3227-7.

[34] A. Zapata, Lymphoid Organs of Teleost Fish .1. Ultrastructure of thymys of Rutilus rutilus, Dev. Comp. Immunol. 5 (1981) 427-436. doi:10.1016/S0145-305X(81)800559.

[35] A.F. Rowley, Collection, separation and identification of fish leukocytes, in: J.S. Stolen, T.C. Fletcher, D.P. Anderson, B.S. Roberson, W.. Van Muiswinkel (Eds.), Tech. Fish Immunol. Fish Immunol. Tech. Commun. 1, 1st Editio, Fair Haven, NJ : SOS Publications, c1993., Fair Haven, New Jersey, 1990: p. 197 pp.

[36] M. Tatner, Surgical techniques in fish immunology, in: J.S. Stolen, T.C. Fletcher, D.P. Anderson, B.S. Roberson, W.. Van Muiswinkel (Eds.), Tech. Fish Immunol. Fish Immunol. Tech. Commun. 1, 1st Editio, Fair Haven, NJ : SOS Publications, c1993., Fair Haven, New Jersey, 1990: p. 197 pp.

[37] M.K. Stoskopf, Clinical examination and procedures, in: Fish Med., W. B. Saun, Philadelphia, 1992: pp. 62-78.

[38] C. Pösel, K. Möller, W. Fröhlich, I. Schulz, J. Boltze, D.C. Wagner, Density Gradient Centrifugation Compromises Bone Marrow Mononuclear Cell Yield, PLoS One. 7 (2012) 1-10. doi:10.1371/journal.pone.0050293.

[39] M.A. Pierrard, K. Roland, P. Kestemont, M. Dieu, M. Raes, F. Silvestre, Fish peripheral blood mononuclear cells preparation for future monitoring applications, 
741

742

743

744

745

746

747

748

749

750

751

752

753

754

755

756

757

758

759

760

761

762

763

[40] F. Panjvini, S. Abarghuei, H. Khara, H.M. Parashkoh, Parasitic infection alters haematology and immunity parameters of common carp, Cyprinus carpio, Linnaeus, 1758, J. Parasit. Dis. 40 (2016) 1540-1543. doi:10.1007/s12639-015-0723-8.

[41] B. Kemenade, A. Groeneveld, B. Rens, J. Rombout, Characterization of Macrophages and Neutrophilic Granulocytes From the Pronephros of Carp (Cyprinus Carpio), J. Exp. Biol. 187 (1994) 143-58. http://www.ncbi.nlm.nih.gov/pubmed/9317515.

[42] D.E. Tillitt, J.P. Giesy, P.O. Fromm, In vitro mitogenesis of peripheral blood lymphocytes from rainbow trout (Salmo gairdneri), Comp Biochem Physiol A. 89 (1988) 25-35. doi:10.1016/0300-9629(88)91134-6.

[43] A. Zapata, B. Diez, T. Cejalvo, C. Gutiérrez-De Frías, A. Cortés, Ontogeny of the immune system of fish, Fish Shellfish Immunol. 20 (2006) 126-136. doi:10.1016/j.fsi.2004.09.005.

[44] D.M. Page, V. Wittamer, J.Y. Bertrand, K.L. Lewis, D.N. Pratt, N. Delgado, S.E. Schale, C. McGue, B.H. Jacobsen, A. Doty, Y. Pao, H. Yang, N.C. Chi, B.G. Magor, D. Traver, An evolutionarily conserved program of B-cell development and activation in zebrafish, Blood. 122 (2013). doi:10.1182/blood-2012-12-471029.

[45] T. Korytár̆, H. Dang Thi, F. Takizawa, B. Köllner, A multicolour flow cytometry identifying defined leukocyte subsets ofrainbow trout (Oncorhynchus mykiss), Fish Shellfish Immunol. 35 (2013) 2017-2019. doi:10.1016/j.fsi.2013.09.025.

[46] A.J. Ulmer, W. Scholz, M. Ernst, E. Brandt, H.D. Flad, Isolation and subfractionation of human peripheral blood mononuclear cells (PBMC) by density gradient centrifugation on Percoll, Immunobiology. 166 (1984) 238-250. doi:10.1016/S01712985(84)80042-X. 
situ experiments to assess effects of constraints linked to caging on ecotoxicity biomarkers of the three-spined stickleback (Gasterosteus aculeatus L.), Fish Physiol. Biochem. 42 (2016) 643-657. doi:10.1007/s10695-015-0166-2.

[48] A. Le Guernic, W. Sanchez, O. Palluel, A. Bado-Nilles, M. Floriani, C. Turies, E. Chadili, C. Della Vedova, I. Cavali??, C. Adam-Guillermin, J.M. Porcher, A. Geffard, S. Betoulle, B. Gagnaire, Acclimation capacity of the three-spined stickleback (Gasterosteus aculeatus, L.) to a sudden biological stress following a polymetallic exposure, Ecotoxicology. 25 (2016) 1478-1499. doi:10.1007/s10646-016-1699-6.

[49] A. Bado-Nilles, S. Jolly, F. Lamand, A. Geffard, B. Gagnaire, C. Turies, J.M. Porcher, W. Sanchez, S. Betoulle, Involvement of fish immunomarkers in environmental biomonitoring approach: Urban and agri-viticultural context, Ecotoxicol. Environ. Saf. 120 (2015) 35-40. doi:10.1016/j.ecoenv.2015.05.021.

[50] B. Gagnaire, A. Bado-Nilles, S. Betoulle, R. Amara, V. Camilleri, I. Cavalié, E. Chadili, L. Delahaut, E. Kerambrun, D. Orjollet, O. Palluel, W. Sanchez, Former uranium mine-induced effects in caged roach: a multiparametric approach for the evaluation of in situ metal toxicity, Ecotoxicology. 24 (2015) 215-231. doi:10.1007/s10646-014-1374-8.

[51] J. Douxfils, C. Fierro-Castro, S.N.M. Mandiki, W. Emile, L. Tort, P. Kestemont, Dietary $\beta$-glucans differentially modulate immune and stress-related gene expression in lymphoid organs from healthy and Aeromonas hydrophila-infected rainbow trout (Oncorhynchus mykiss), Fish Shellfish Immunol. 63 (2017) 285-296. doi:10.1016/j.fsi.2017.02.027.

[52] M. Witeska, J. Biardzka, J. Kniaz, The effects of heparin concentration, storage time, and temperature on the values of hematological parameters in Cyprinus carpio, Turkish J. Vet. Anim. Sci. 41 (2017) 351-356. doi:10.3906/vet-1611-35. 
791

792

793

794

795

796

797

798

799

800

801

802

803

804

805

806

807

808

809

810

811

812

813

814

815

[53] C.F. Ellsaesser, L.W. Clem, Haematological and immunological changes in channel

catfish stressed by handling and transport, J. Fish Biol. 28 (1986) 511-521.

doi:10.1111/j.1095-8649.1986.tb05187.x.

[54] S.A.D.S. Perera, A. Pathiratne, Haemato-Immunological and Histological Responses in Nile Tilapia, Oreochromis niloticus Exposed to Titanium Dioxide Nanoparticles, Sri Lanka J. Aquat. Sci. 17 (2012) 1-18. doi:http://dx.doi.org/10.4038/sljas.v17i0.6852.

[55] A.L. Pulsford, S. Lemaire-Gony, M. Tomlinson, N. Collingwood, P.J. Glynn, Effects of acute stress on the immune system of the dab, Limanda limanda, Comp. Biochem. Physiol. Part C Comp. 109 (1994) 129-139. doi:10.1016/0742-8413(94)00053-D.

[56] M.C. Sueiro, M.G. Palacios, Immunological and health-state parameters in the Patagonian rockfish Sebastes oculatus. Their relation to chemical stressors and seasonal changes, Fish Shellfish Immunol. 48 (2016) 71-78. doi:10.1016/j.fsi.2015.11.021.

[57] Y.D. Zebral, B. Zafalon-Silva, M.W. Mascarenhas, R.B. Robaldo, Leucocyte profile and growth rates as indicators of crowding stress in pejerrey fingerlings (Odontesthes bonariensis), Aquac. Res. 46 (2015) 2270-2276. doi:10.1111/are.12384.

[58] C. Faggio, F. Arfuso, G. Piccione, A. Zumbo, F. Fazio, Effect of Three Different Anticoagulants and Storage Time on Haematological Parameters of Mugil cephalus (Linneaus, 1758), Turkish J. Fish. Aquat. Sci. 14 (2014) 615-621. doi:10.4194/13032712-v14.

[59] F.P. Montanha, A.C. Fredianelli, R. Wagner, S.R. Sacco, D.C.C. Rocha, C.T. Pimpão, Clinical, biochemical and haemathological effects in Rhamdia quelen exposed to cypermethrin, Arq. Bras. Med. Vet. E Zootec. 66 (2014) 697-704. doi:10.1590/167841625934.

[60] R. Urban-Chmiel, U. Lisiecka, A. Chłopaś, Ł. Kurek, A. Wernicki, The influence of 
Pol. J. Vet. Sci. 14 (2011) 663-665. doi:10.2478/v10181-011-0099-3.

818

819

820

821

822

823

824

825

826

827

828

829

830

831

832

833

834

835

836

837

[61] E. Siegl, B. Nebe, H. Blunk, J. Rychly, Detection of mitogen induced stimulation of leukocytes from the rainbow trout ( Oncorhynchus mykiss ) by flow cytometric analysis of intracellular calcium, Comp. Biochem. Physiol. Part A. 119 (1998) 915923. doi:10.1016/S1095-6433(98)00003-8.

[62] U. Fischer, E.O. Koppang, T. Nakanishi, Teleost T and NK cell immunity, Fish Shellfish Immunol. 35 (2013) 197-206. doi:10.1016/j.fsi.2013.04.018.

[63] G. Scapigliati, Functional aspects of fish lymphocytes, Dev. Comp. Immunol. 41 (2013) 200-208. doi:10.1016/j.dci.2013.05.012.

[64] Y. Suzuki, T. Iida, Fish granulocytes in the process of inflammation, Annu. Rev. Fish Dis. 2 (1992) 149-160. doi:10.1016/0959-8030(92)90061-2.

[65] J.J. Havixbeck, D.R. Barreda, Neutrophil Development, Migration, and Function in Teleost Fish, Biology (Basel). 4 (2015) 715-734. doi:10.3390/biology4040715.

[66] A.K. Davis, D.L. Maney, J.C. Maerz, The use of leukocyte profiles to measure stress in vertebrates: A review for ecologists, Funct. Ecol. 22 (2008) 760-772. doi:10.1111/j.1365-2435.2008.01467.x.

[67] A. Bado-Nilles, S. Jolly, J.M. Porcher, O. Palluel, A. Geffard, B. Gagnaire, S. Betoulle, W. Sanchez, Applications in environmental risk assessment of leucocyte apoptosis, necrosis and respiratory burst analysis on the European bullhead, Cottus sp., Environ. Pollut. 184 (2014) 9-17. doi:10.1016/j.envpol.2013.07.049.

[68] C.J. Secombes, The nonspecific immune system: cellular defences, in: G. Iwama, N. Teruyuki (Eds.), Fish Immune Syst. Org. Pathog. Environ., Academic Press, San Diego, 1996: pp. 63-103. 

characterize fish blood granulocytes in species of special concern and determine potential for function testing, Fish Shellfish Immunol. 30 (2011) 646-652. doi:10.1016/j.fsi.2010.12.024.

844

845

846

847

848

849

850

851

852

853

854

855

856

857

858

859

860

861

[70] A. do Vale, A. Afonso, M.T. Silva, The professional phagocytes of sea bass (Dicentrarchus labrax L.): cytochemical characterisation of neutrophils and macrophages in the normal and inflamed peritoneal cavity., Fish Shellfish Immunol. 13 (2002) 183-198. doi:10.1006/fsim.2001.0394.

[71] M. Sepulcre, P. Pelegrín, V. Mulero, J. Meseguer, Characterisation of gilthead seabream acidophilic granulocytes by a monoclonal antibody unequivocally points to their involvement in fish phagocytic response, Cell Tissue Res. 308 (2002) 97-102. doi:10.1007/s00441-002-0531-1.

[72] J. Li, D.R. Barreda, Y.-A. Zhang, H. Boshra, A.E. Gelman, S. LaPatra, L. Tort, J.O. Sunyer, B lymphocytes from early vertebrates have potent phagocytic and microbicidal abilities., Nat. Immunol. 7 (2006) 1116-1124. doi:10.1038/ni1389.

[73] H.S. Øverland, E.F. Pettersen, A. Rønneseth, H.I. Wergeland, Phagocytosis by B-cells and neutrophils in Atlantic salmon (Salmo salar L.) and Atlantic cod (Gadus morhua L.)., Fish Shellfish Immunol. 28 (2010) 193-204. doi:10.1016/j.fsi.2009.10.021. 
Figure 1. Gating method for cytograms analysis. Example for head-kidney leukocytes isolated by density gradient or hypotonic lysis. Head-kidney leukocytes were purified by density gradient (A, B, C) or hypotonic lysis (D, E, F). P1 = Leukocytes gate (A and D); P2 =

877 Gate of excluded doublets in FSC-H/FSC-A cytograms (B and E); P3 = impurities (C and F); Leukocytes were recorded in P1 gate with P2 and P3 gates exclusion from counts (Total of 87910000 events in P1).

Figure 2. Gating method used to determine leukocyte subpopulations distribution in cell suspensions. Leukocytes subpopulations were gated as lymphocytes + thrombocytes (Ly), monocytes/macrophages (M) and granulocytes (Gr).

Figure 3. Cell mortality measurement. A - The pick in the left part was related to viable leukocytes autofluorescence. Dead or senescent cells were positively marked with Propidium 

marked cells. B - PI-marked cells were colored in red within the total leukocytes population.

889

890

891

892

893

894

895

896

897

898

899

900

901

902

903

904

905

906

907

908

909

910

911

912

\section{5 column fitting image}

Figure 4. Phagocytosis assay. A - Fluorescence of cells ingesting one bead (mean fluorescence in M1) or 3 beads and more (mean fluorescence in M2). B - dotplots presentation of cells ingesting one bead (blue) and cells ingesting 3 beads and more (red). Uncolored ones represent cells ingesting two beads.

1.5 column fitting image

Figure 5. Oxidative activity assay. A, B - Mean fluorescence of DCFH measured in headkidney lymphocytes (blue), in monocytes/macrophages (pink) and in granulocytes (green). C, D - Mean fluorescence of DCFH measured in cells unstimulated or stimulated with PMA in function of their complexity (SSC-A).

Whole page fitting image

Figure 6. Leukocytes cytograms of spleen, head-kidney and blood tissues in function of purification methods. Leukocytes from spleen, head-kidney and blood cell suspensions were purified by density gradient or by hypotonic lysis of erythrocytes. After cell isolation, samples were diluted to 1:10 in PBS and analysed for leukocytes composition by flow cytometry using FSC (size) / SSC (complexity) parameters. Cytograms were acquired just after cells purification (no incubation) and after $12 \mathrm{~h}$ of cell incubation.

\section{2 column fitting image}

Figure 7. Sub-populations leukocytes distributions in spleen, head-kidney and blood tissues in function of cell purification methods. Stacked bars represent leukocytes composition of tissue either purified by density gradient (DG) or by hypotonic lysis of erythrocytes (HL). Cell suspension analysis were realized immediately after isolation procedures $(0 \mathrm{~h})$ or after a $12 \mathrm{~h}$ of incubation of cell suspension before analysis $(12 \mathrm{~h})$. Bar height represent median of $\mathrm{n}=10$ observations and the total bar height represent $100 \%$ of each leukocytes population. 
914

915

916

917

918

919

920

921

922

923

924

925

926

927

928

929

930

931

932

933

granulocytes. Asterisks above bars indicate significant differences between data obtained for the two purification methods $(p<0.05)$

\section{2 columns fitting image}

Figure 8. Leukocytes mortality in spleen, head-kidney and blood tissues in function of cell purification methods. Cell necrosis was measured by flow cytometry as percentages of PIpositive cells for total leukocytes population (T) or for each subpopulations: lymphocytes (L), monocytes/macrophages (M) and granulocytes (G) isolated from spleen (A), head-kidney (B) and blood (C). For each tissue, cell suspensions were separated in two equal volumes and purified either by density gradient (dark grey boxes) or by hypotonic lysis of erythrocytes (grey boxes). Boxplots represent 25th and 75 th percentiles over and below the median (line within the box) for $n=10$ observations. Bars at the top and bottom of boxes indicate 10 th and 90th percentiles. Cell suspension analysis were realized immediately after isolation procedures $(0 \mathrm{~h})$ or after a $12 \mathrm{~h}$ of incubation of cell suspension before analysis (12h). Asterisks above bars indicate significant differences between data obtained for the two purification methods $(*: p<0.05 ; * *: p<0.01)$.

\section{2 column fitting image}

Figure 9. Basal intracellular ROS in spleen, head-kidney and blood leukocytes in function of cell purification methods. Basal intracellular ROS were measured by flow cytometry as mean fluorescence of DCF in total leukocytes population $(\mathrm{T})$ or for each leukocyte subpopulations: lymphocytes (L), monocytes/macrophages (M) and granulocytes (G) isolated from spleen (A), head-kidney (B) and blood (C). For each tissue, cell suspensions were separated in two equal volumes and purified either by density gradient (dark grey boxes) or by hypotonic lysis of erythrocytes (grey boxes). Boxplots represent 25th and 75 th percentiles over and below the median (line within the box) for $n=10$ observations. Bars at the top and bottom of boxes indicate 10th and 90th percentiles. Cell suspension analysis were realized immediately after isolation procedures $(0 \mathrm{~h})$ or after a $12 \mathrm{~h}$ of incubation of cell suspension 
941 obtained for the two purification methods (*: $p<0.05 ; * * *: p<0.001)$.

942

943

944

945

946

947

948

Tables:

949

Table 1. Total cell numbers (cell per mL) obtained after leukocytes isolation in spleen,

950

head-kidney and blood tissues. Cell numerations were realized by flow cytometry on total

951

leukocyte cell suspensions isolated from spleen, head-kidney and blood. For each tissue, cell

952

suspensions were separated in two equal volumes and purified either by density gradient or by

953

hypotonic lysis of erythrocytes. Numeric data are median and min and max values obtained

from $n=10$ observations. Cell suspension analysis were realized immediately after isolation

955 procedures $(0 \mathrm{~h})$.

\begin{tabular}{cc|cc|c|cc}
\hline & \multicolumn{3}{c|}{ Density gradient } & \multicolumn{3}{c}{ Hypotonic lysis } \\
\cline { 2 - 7 } & Median & Min & Max & Median & Min & Max \\
\hline Spleen & $5.26 \times 10^{6}$ & $1.34 \times 10^{6}$ & $7.85 \times 10^{6}$ & $4.40 \times 10^{6}$ & $0.72 \times 10^{6}$ & $10.0 \times 10^{6}$ \\
\hline Head-kidney & $8.93 \times 10^{6}$ & $4.69 \times 10^{6}$ & $20.4 \times 10^{6}$ & $14 \times 10^{6}$ & $7.83 \times 10^{6}$ & $24.1 \times 10^{6}$ \\
\hline Blood & $0.57 \times 10^{6}$ & $0.004 \times 10^{3}$ & $4.55 \times 10^{6}$ & $0.36 \times 10^{6}$ & $0.02 \times 10^{6}$ & $1.24 \times 10^{6}$ \\
\hline
\end{tabular}

Table 2. Samples purity after isolation. Results were expressed as number of cells per millilitre. Numeric data are median and $\min$ and $\max$ values obtained from $\mathrm{n}=10$ observations. Cell suspension analysis were realized immediately after isolation procedures 
on the same line.

\begin{tabular}{cc|cc|c|cc}
\hline & \multicolumn{3}{c|}{ Density gradient } & \multicolumn{3}{c}{ Hypotonic lysis } \\
\cline { 2 - 7 } & Median & Min & Max & Median & Min & Max \\
\hline Spleen & $\underline{97.6 \% *}$ & $93.0 \%$ & $99.0 \%$ & $94.8 \%$ & $91.9 \%$ & $97.5 \%$ \\
\hline Head-kidney & $\underline{96.7 \% *}$ & $95.2 \%$ & $97.3 \%$ & $94.7 \%$ & $92.7 \%$ & $96.0 \%$ \\
\hline Blood & $\underline{97.4 \% *}$ & $90.3 \%$ & $99.0 \%$ & $89.2 \%$ & $74.6 \%$ & $97.3 \%$ \\
\hline
\end{tabular}

Table 3. Activated intracellular ROS production in spleen, head-kidney and blood

ROS were measured by flow cytometry in total leukocytes population or for each leukocyte subpopulations (lymphocytes, monocytes/macrophages and granulocytes) isolated from

971 spleen, head-kidney and blood. For each tissue, cell suspensions were separated in two equal

972 volumes and purified either by density gradient or by hypotonic lysis of erythrocytes. The

973 results were expressed in stimulation index as the ratio between the mean fluorescence measured in stimulated cells (DCFH-DA + PMA) and the basal mean fluorescence of control (DCFH-DA only). Numeric data are median and min and max values obtained from $\mathrm{n}=10$ observations. Cell suspension analysis were realized immediately after isolation procedures (0h) or after a $12 \mathrm{~h}$ of incubation of cell suspension before analysis (12h). Asterisks indicate significant differences between data obtained for the two purification methods $(*$ : $\mathrm{p}<0.05)$. 
985

986

987

988

989

990

991

992

993

\begin{tabular}{|c|c|c|c|c|c|c|c|c|}
\hline & & $C$ & & ity grac & ient & & otonic & vsis \\
\hline & & cens & Median & Min & Max & Median & Min & $\operatorname{Max}$ \\
\hline & & Total leucocytes & $7 . .37$ & 0.71 & 14.29 & 6.52 & 2.75 & 25.56 \\
\hline & & Lymphocytes & 6.25 & 0.64 & 11.73 & 4.25 & 2.14 & 13.27 \\
\hline & incubation & Monocytes / Macrophages & 5.12 & 0.76 & 10.41 & 4.24 & 2.02 & 18.86 \\
\hline & & Granulocytes & 31.26 & 1.92 & 86.59 & 19.90 & 5.30 & 61.38 \\
\hline & & Total leucocytes & 6.73 & 3.04 & 13.94 & 5.60 & 2.18 & 7.50 \\
\hline & $12 \mathrm{~h}$ & Lymphocytes & $\underline{6.80^{*}}$ & 3.16 & 13.33 & $\underline{2.88}$ & 1.58 & 6.55 \\
\hline & incubation & Monocytes / Macrophages & 5.64 & 2.31 & 12.90 & 2.56 & 1.64 & 5.60 \\
\hline & & Granulocytes & 10.23 & 1.59 & 65.15 & 9.66 & 3.84 & 29.67 \\
\hline & & Total leucocytes & 23.38 & 12.04 & 113.75 & 48.78 & 18.01 & 160.38 \\
\hline & No & Lymphocytes & 20.18 & 6.83 & 92.17 & 33.34 & 10.96 & 124.03 \\
\hline & incubation & Monocytes / Macrophages & 14.32 & 6.08 & 78.06 & 29.45 & 9.94 & 110.61 \\
\hline Head- & & Granulocytes & 41.56 & 19.01 & 249.32 & 60.97 & 28.95 & 170.86 \\
\hline kidney & & Total leucocytes & 4.32 & 2.47 & 19.48 & 7.28 & 0.88 & 87.32 \\
\hline & $12 \mathrm{~h}$ & Lymphocytes & 5.55 & 1.81 & 17.36 & 6.00 & 1.07 & 30.93 \\
\hline & incubation & Monocytes / Macrophages & 3.11 & 2.43 & 14.95 & 5.08 & 1.29 & 40.13 \\
\hline & & Granulocytes & 4.47 & 1.46 & 27.99 & 8.94 & 0.50 & 110.47 \\
\hline & & Total leucocytes & 4.66 & 2.36 & 24.34 & 8.24 & 1.58 & 28.15 \\
\hline & & Lymphocytes & 3.59 & 1.64 & 23.19 & 2.38 & 1.55 & 5.62 \\
\hline Blood & incubation & Monocytes / Macrophages & 6.99 & 1.26 & 24.03 & 4.05 & 1.79 & 13.38 \\
\hline & & Granulocytes & 9.18 & 2.43 & 208.39 & 21.67 & 7.97 & 151.05 \\
\hline & $12 \mathrm{~h}$ & Total leucocytes & 2.58 & 0.87 & 7.49 & 4.53 & 1.89 & 11.38 \\
\hline
\end{tabular}




\begin{tabular}{cccc|cc|c|cc}
\hline \multirow{2}{*}{ incubation } & \multicolumn{2}{c|}{ Lymphocytes EPTED } & 2.90* & 0.88 & 7.17 & $\underline{1.40}$ & 1.02 & 2.39 \\
\cline { 2 - 9 } & Monocytes / Macrophages & 1.45 & 0.88 & 5.57 & 1.77 & 0.93 & 2.93 \\
\cline { 2 - 9 } & Granulocytes & 11.16 & 0.17 & 19.36 & 12.03 & 3.81 & 43.56 \\
\hline
\end{tabular}

994

995

996

997

998

999

1000

1001

Table 4. Phagocytosis activity of spleen, head-kidney and blood leukocytes in function of

1002

cell purification methods. The phagocytic activity corresponds to percentages of cell

1003

ingesting three beads and more. Phagocytic activity was measured by flow cytometry for total

1004

leukocytes populationpopulation or for each leukocyte subpopulations (lymphocytes,

1005

monøcytes/macrophages and granulocytes) isolated from spleen, head-kidney and blood. For

1006

each tissue, cell suspensions were separated in two equal volumes and purified either by

1007

density gradient or by hypotonic lysis of erythrocytes. Numeric data are median and min and

1008

max values obtained from $\mathrm{n}=10$ observations. Cell suspension analysis were realized

1009

immediately after isolation procedures $(0 \mathrm{~h})$ or after a $12 \mathrm{~h}$ of incubation of cell suspension

1010 before analysis (12h). Asterisks indicate significant differences between data obtained for the

1011 two purification methods $(*$ : $\mathrm{p}<0.05)$. Significant differences are indicated with underlined

1012 medians on the same line.

\begin{tabular}{clllll|lll}
\hline & & \multicolumn{3}{c}{ Density gradient } & \multicolumn{3}{c}{ Hypotonic lysis } \\
\cline { 3 - 8 } & & Median & Min & Max & Median & Min & Max \\
\hline \multirow{2}{*}{ Spleen } & No incubation & $61.58 \%$ & $23,64 \%$ & $84,78 \%$ & $55,32 \%$ & $18,91 \%$ & $82,92 \%$ \\
\cline { 2 - 8 } & 12h incubation & $67,09 \%$ & $49,77 \%$ & $79,49 \%$ & $73,65 \%$ & $56,35 \%$ & $80,51 \%$ \\
\hline Head-kidney & No incubation & $\underline{66,35 \% *}$ & $29,17 \%$ & $87,96 \%$ & $\underline{42,44 \%}$ & $27,46 \%$ & $64,10 \%$ \\
\hline
\end{tabular}




\begin{tabular}{cccc|cc|c|cc}
\hline & $12 \mathrm{~h}$ incubation & $\mathrm{A}$ & $68,65 \%$ & $48,89 \%$ & $83,32 \%$ & $57,75 \%$ & $36,01 \%$ & $78,55 \%$ \\
\hline \multirow{2}{*}{ Blood } & No incubation & $65,86 \%$ & $37,46 \%$ & $97,37 \%$ & $46,70 \%$ & $34,16 \%$ & $77,42 \%$ \\
\cline { 2 - 8 } & $12 \mathrm{~h}$ incubation & $60,92 \%$ & $51,61 \%$ & $65,72 \%$ & $53,63 \%$ & $44,82 \%$ & $92,95 \%$ \\
\hline
\end{tabular}

1013

1014

1015

1016

1017

1018

1019

1020

Table 5. Numbers of ingested beads in spleen, head-kidney and blood leukocytes in

1021

function of cell purification methods. The number of phagocytosed beads was calculated by

1022

dividing the mean fluorescence of events corresponding to three and more beads-ingesting

1023

cells by the fluorescence of events corresponding to only one bead-ingesting cells. Numbers

1024

of ingested beads was measured by flow cytometry for total leukocytes population er for each

1025

leukøcyte subpopulations (lymphøcytes, monøcytes/macrophages and granuløcytes)-isolated

1026

from spleen, head-kidney and blood. For each tissue, cell suspensions were separated in two

1027

equal volumes and purified either by density gradient or by hypotonic lysis of erythrocytes.

1028

Numeric data are median and min and max values obtained from $n=10$ observations. Cell

1029

suspension analysis were realized immediately after isolation procedures $(0 \mathrm{~h})$ or after a $12 \mathrm{~h}$ of

1030 incubation of cell suspension before analysis (12h). Asterisks indicate significant differences

1031 between data obtained for the two purification methods $(*: \mathrm{p}<0.05)$. Significant differences are indicated with underlined medians on the same line.

\begin{tabular}{ccc|cc|c|cc}
\hline & \multicolumn{3}{c|}{ Density gradient } & \multicolumn{3}{c}{ Hypotonic lysis } \\
\cline { 3 - 7 } & & Median & Min & Max & Median & Min & Max \\
\hline Spleen & No incubation & 6.67 & 4.94 & 9.45 & 6.80 & 4.86 & 8.51 \\
\hline
\end{tabular}




\begin{tabular}{|c|c|c|c|c|c|c|c|}
\hline & $12 \mathrm{~h}$ incubation & $8.44 \mathrm{~N}$ & 7.79 & 9.11 & 8.89 & 7.12 & 9.85 \\
\hline \multirow{2}{*}{ Head-kidney } & No incubation & 7.43 & 5.18 & 8.93 & 6.56 & 4.91 & 7.68 \\
\hline & $12 \mathrm{~h}$ incubation & $\underline{8.76 * *}$ & 5.44 & 10.43 & $\underline{7.41}$ & 5.72 & 8.52 \\
\hline \multirow{2}{*}{ Blood } & No incubation & 7.08 & 6.00 & 11.15 & 7.27 & 6.46 & 9.63 \\
\hline & 12h incubation & 7.99 & 6.83 & 8.86 & 8.70 & 5.10 & 12.06 \\
\hline
\end{tabular}

1033 
Table 6. Correlations ( $\rho$ of Spearman) between leukocytes distributions and cell immune responses in function of cell purification methods. Values of correlation coefficients were significant at $p<0.05$ (bold characters). After Fisher transformation, differences between $\rho$ values were evaluated with a Z-test and were noticed as follow (* $p<0.05$ no incubation vs 12 incubation for same tissues and purification methods; \# $p<0.05$ density gradient vs hypotonic lysis for same tissues and incubation time). Ly.=Lymphocytes; M.=Monocytes/macrophages; Gr.=Granulocytes; Phago=Phagocytosis.

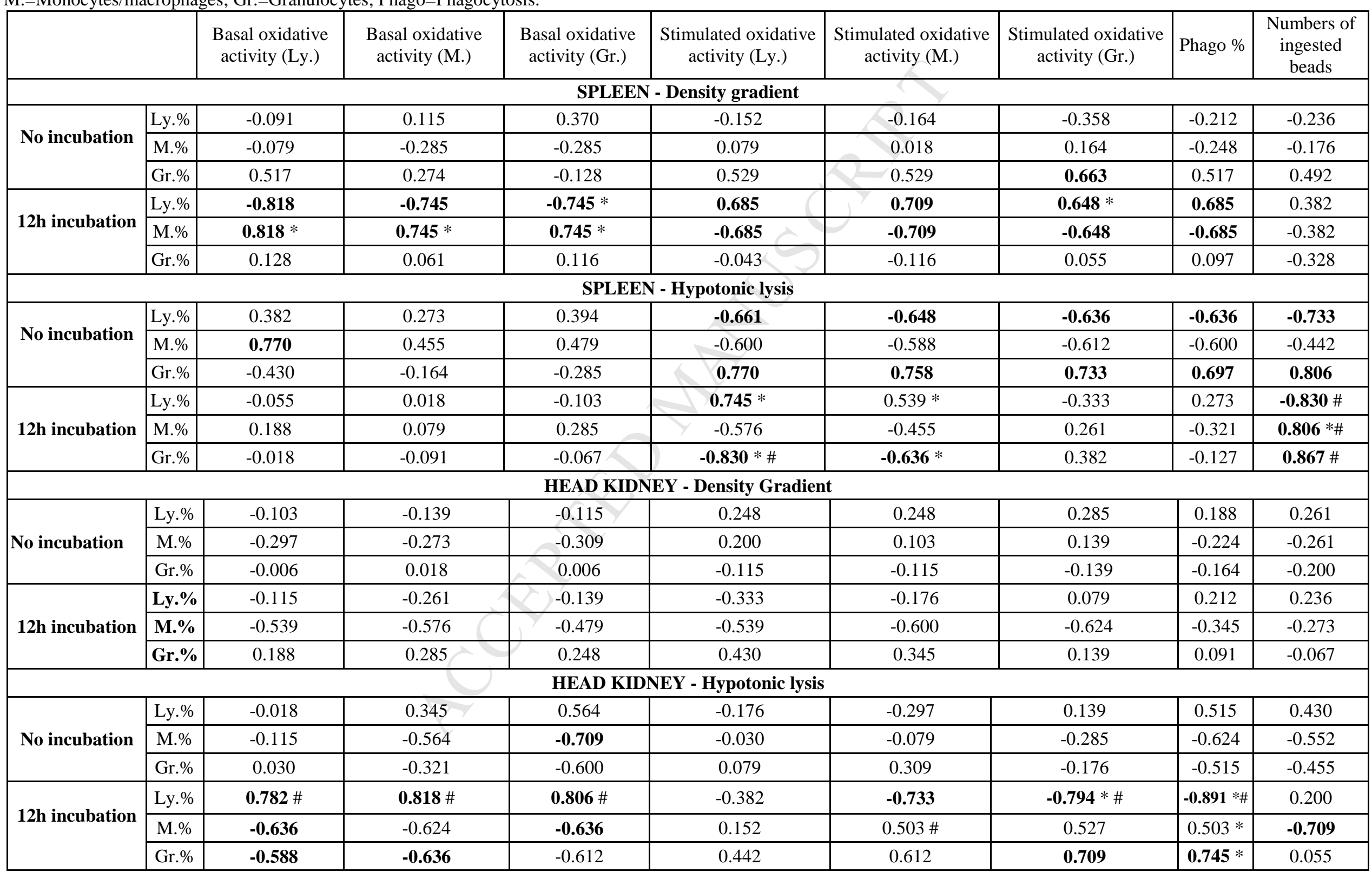




\begin{tabular}{|c|c|c|c|c|c|c|c|c|c|}
\hline & & \begin{tabular}{|l} 
Basal oxidative \\
activity (Ly.)
\end{tabular} & $\begin{array}{l}\text { Basal oxidative } \\
\text { activity (M.) }\end{array}$ & $\begin{array}{l}\text { Basal oxidative } \\
\text { activity (Gr.) }\end{array}$ & $\begin{array}{l}\text { Stimulated oxidative } \\
\text { activity (Ly.) }\end{array}$ & $\begin{array}{l}\text { Stimulated oxidative } \\
\text { activity (M.) }\end{array}$ & $\begin{array}{l}\text { Stimulated oxidative } \\
\text { activity (Gr.) }\end{array}$ & Phago \% & \begin{tabular}{|l} 
Numbers of \\
ingested beads
\end{tabular} \\
\hline \multicolumn{10}{|c|}{ BLOOD - Density Gradient } \\
\hline \multirow{3}{*}{ No incubation } & Ly.\% & $-0,442$ & $-0,418$ & $-0,333$ & $-0,539$ & $-0,309$ & 0,103 & 0,018 & $-0,139$ \\
\hline & M.\% & 0,503 & 0,442 & 0,127 & 0,588 & 0,248 & 0,030 & $-0,333$ & $-0,236$ \\
\hline & Gr.\% & $-0,224$ & $-0,139$ & 0,285 & 0,188 & 0,333 & $-0,467$ & 0,467 & 0,552 \\
\hline \multirow{3}{*}{$12 \mathrm{~h}$ incubation } & Ly.\% & $0,600 *$ & $0,667 *$ & 0,350 & 0,767 & 0,900 & $\mathbf{0 , 8 1 7}$ & 0,567 & $-0,067$ \\
\hline & M.\% & $-0,600 *$ & $-0,717 *$ & $-0,200$ & $-0,800$ & $-0,933$ & $-0,833$ & $-0,500$ & $-0,033$ \\
\hline & Gr.\% & $-0,600$ & $-0,600$ & $-0,383$ & $-0,700$ & $-0,750$ & $-0,650$ & $-0,483$ & 0,033 \\
\hline \multicolumn{10}{|c|}{ BLOOD - Hypotonic lysis } \\
\hline \multirow{3}{*}{ No incubation } & Ly.\% & $-0,217$ & 0,000 & 0,083 & $-0,417$ & $-0,183$ & $-0,050$ & 0,188 & 0,127 \\
\hline & M.\% & 0,633 & $-0,133$ & $-0,283$ & 0,017 & $-0,250$ & $-0,267$ & $-0,455$ & $-0,418$ \\
\hline & Gr.\% & $-0,233$ & 0,417 & 0,100 & 0,383 & 0,650 & $0,567 \#$ & 0,042 & 0,115 \\
\hline \multirow{3}{*}{ 12h incubation } & Ly.\% & 0,000 & 0,071 & $-0,310$ & 0,238 & $-0,286 \#$ & 0,071 & 0,285 & 0,248 \\
\hline & M.\% & $0,548 \#$ & $-0,143$ & 0,619 & $-0,667$ & 0,095 \# & $-0,190$ & $-0,358$ & $-0,261$ \\
\hline & Gr.\% & $-0,238$ & 0,238 & 0,381 & 0,000 & $0,381 \#$ & 0,000 & $-0,079$ & $-0,079$ \\
\hline
\end{tabular}

1040

1041

1042

1043

1044

1045

1046

1047

1048

1049

1050 


\begin{tabular}{|c|c|c|c|c|c|c|}
\hline Tissue & Fish species & Separation type & Lymphocytes \% & $\begin{array}{c}\text { Monocytes/ } \\
\text { macrophages\% }\end{array}$ & Granulocytes\% & References \\
\hline \multirow{6}{*}{ Spleen } & Gasterosteus aculeatus & Organ crushing (Flow cytometry) & $53.91-86.21$ & & & Le Guernic et al. 2016 [48] \\
\hline & Cottus sp. & Organ crushing (Flow cytometry) & $32.3-85.1$ & \multicolumn{2}{|c|}{$14.9-67.7$} & Bado-Nilles et al. 2015 [49] \\
\hline & Oncorhynchus mykiss & Sepracell-MN (1.062-1.098) & $10-98$ & $0.0-13$ & $1.8-50$ & Congleton et al. 1990 [16] \\
\hline & Rutilus rutilus & Organ crushing (Flow cytometry) & $82-88$ & \multicolumn{2}{|c|}{$12-18$} & Gagnaire et al. 2015 [50] \\
\hline & Rutilus rutilus & Ficoll ${ }^{\circledR}(1.077)$ & 82.34 & 13.14 & 2.24 & Samai et al. \\
\hline & Rutilus rutilus & Hypotonic lysis (distilled water) & 48.64 & 17.75 & 31.04 & Samai et al. \\
\hline \multirow{7}{*}{$\begin{array}{l}\text { Head- } \\
\text { kidney }\end{array}$} & Oncorhynchus mykiss & Sepracell-MN (1.062-1.098) & $18-68$ & $0.8-33$ & $18-57$ & Congleton et al. 1990 [16] \\
\hline & Oncorhynchus mykiss & Hypotonic lysis (distilled water) & 79.4 & 6 & 14.3 & Crippen et al. 2001 [23] \\
\hline & Oncorhynchus mykiss & Percoll® $(1.048-1.070)$ & 75.1 & 5.3 & 18.8 & Crippen et al. 2001 [23] \\
\hline & Oncorhynchus mykiss & Ficoll@ (1.077) & N.E. & \multicolumn{2}{|c|}{54.7} & $\begin{array}{c}\text { Chilmonczyk and Monge } 1999 \\
\text { [9] }\end{array}$ \\
\hline & Cyprinus carpio & Percoll® $(1.020-1.093)$ & 62 & 18 & 20 & Kemenade et al. 1994 [41] \\
\hline & Rutilus rutilus & Ficoll ${ }^{\circledR}(1.077)$ & 65.29 & 12.33 & 19.58 & Samai et al. \\
\hline & Rutilus rutilus & Hypotonic lysis (distilled water) & 40.09 & 15.98 & 40.80 & Samai et al. \\
\hline \multirow{15}{*}{ Blood } & Oncorhynchus mykiss & Histopaque (1.077) & 93.1 & 0.5 & 6 & Crippen et al. 2001 [23] \\
\hline & Oncorhynchus mykiss & Hypotonic lysis (distilled water) & 91.9 & 0.4 & 7.4 & Crippen et al. 2001 [23] \\
\hline & Oncorhynchus mykiss & Total blood (Flow cytometry) & 90.61 & & 4.78 & Douxfils et al. 2017 [51] \\
\hline & Cyprinus carpio & Smears & 96.5 & & 2.5 & Witeska et al. 2017 [52] \\
\hline & Oncorhynchus mykiss & Total blood (Flow cytometry) & 36.5 & \multicolumn{2}{|c|}{5} & Korytáŕ et al. 2013 [45] \\
\hline & Oncorhynchus mykiss & Percoll@ $(1.075)$ & 58.6 & \multicolumn{2}{|c|}{5} & Korytář et al. 2013 [45] \\
\hline & Ictalurus punctatus & Smears & 43 & 1.6 & 3.5 & Ellsaesser and Clem 1986 [53] \\
\hline & Oreochromis niloticus & Smears & $40.6-41.5$ & $9.3-10.6$ & $47.8-48.9$ & Perera and Pathiratne 2012 [54] \\
\hline & Limanda limanda & \multicolumn{2}{|c|}{10} & \multicolumn{2}{|c|}{10} & Pulsford et al. 1994 [55] \\
\hline & Sebastes oculatus & Smears & 95 & 1.5 & 3 & Sueiro and Palacios 2016 [56] \\
\hline & Odontesthes bonariensis & Smears & 75.3 & 13.3 & 9.6 & Zebral et al. 2015 [57] \\
\hline & Mugil cephalus & Smears & 90 & 2.5 & 6.7 & Faggio et al. 2014 [58] \\
\hline & Rhamdia quelen & Neubauer chamber & & & 8 & Montanha et al. 2014 [59] \\
\hline & Rutilus rutilus & Ficoll ${ }^{\circledR}(1.077)$ & 87.66 & 9.74 & 1.45 & Samai et al. \\
\hline & Rutilus rutilus & Hypotonic lysis (distilled water) & 72.85 & 14.22 & 10.74 & Samai et al. \\
\hline
\end{tabular}



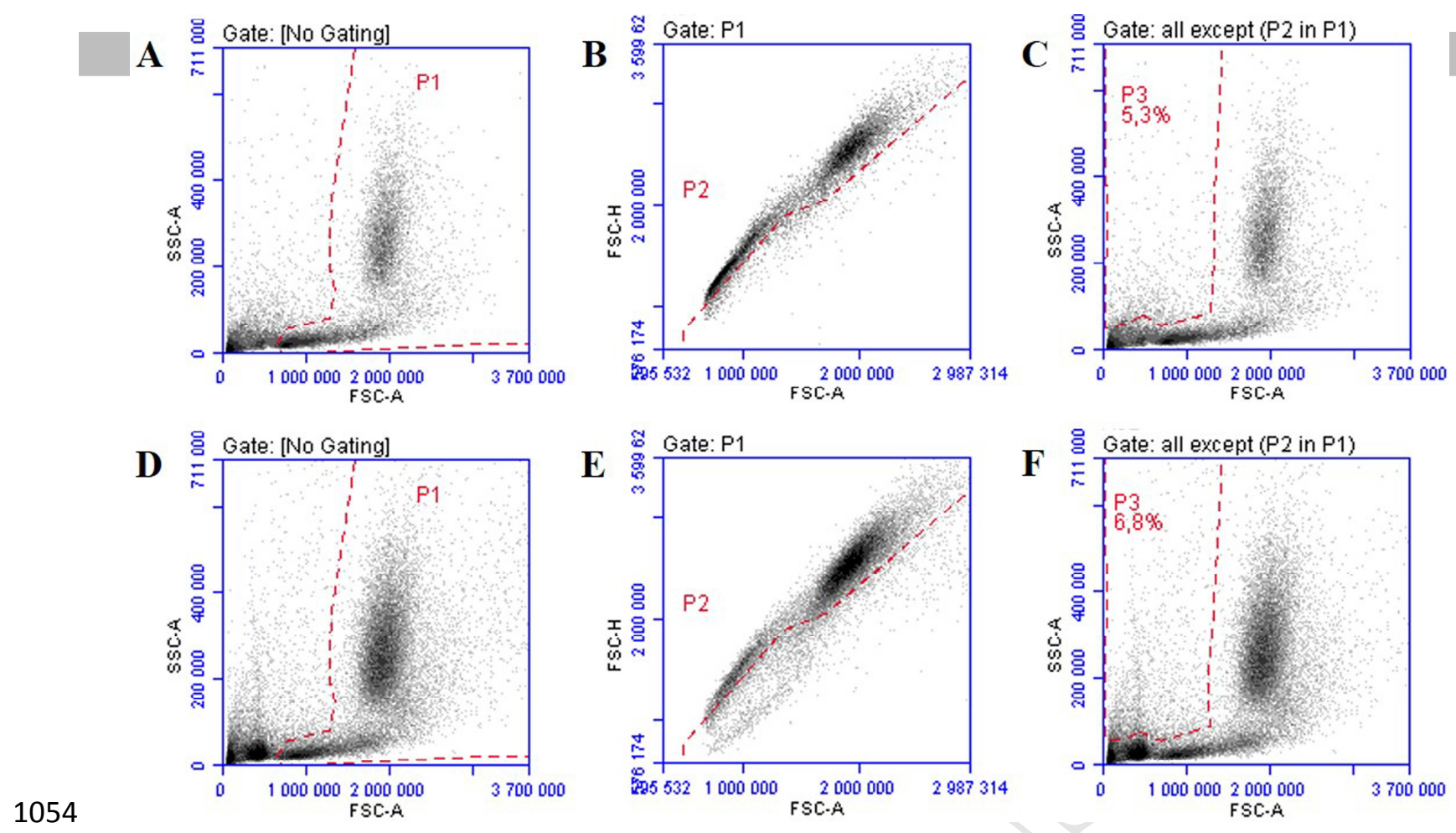

\section{$1055 \quad$ Fig.1}

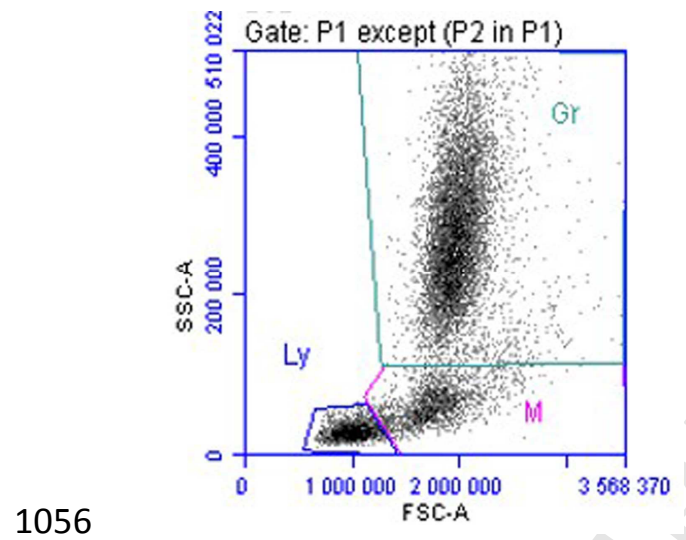

$1057 \quad$ Fig.2 


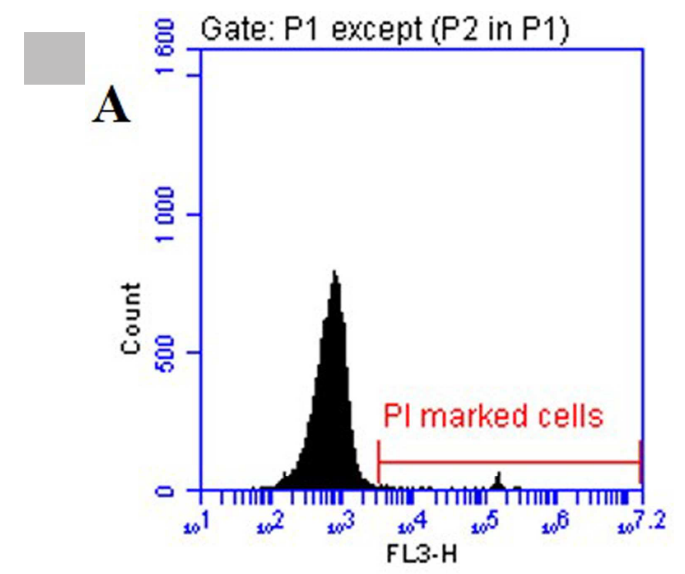

1058

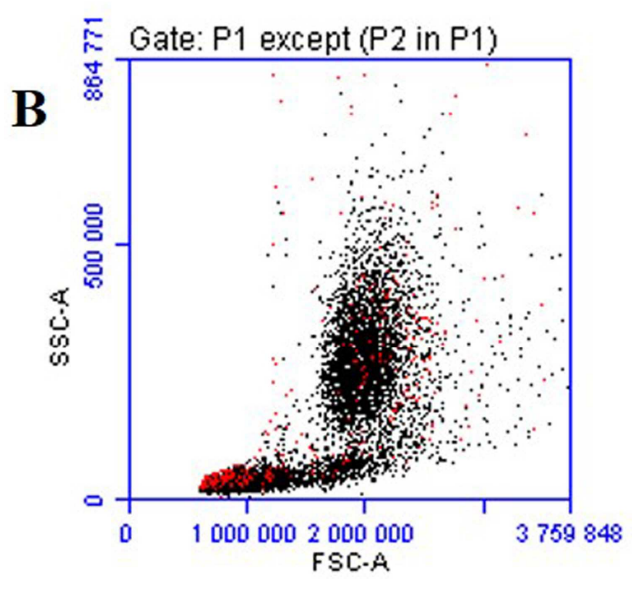

$1059 \quad$ Fig.3

1060
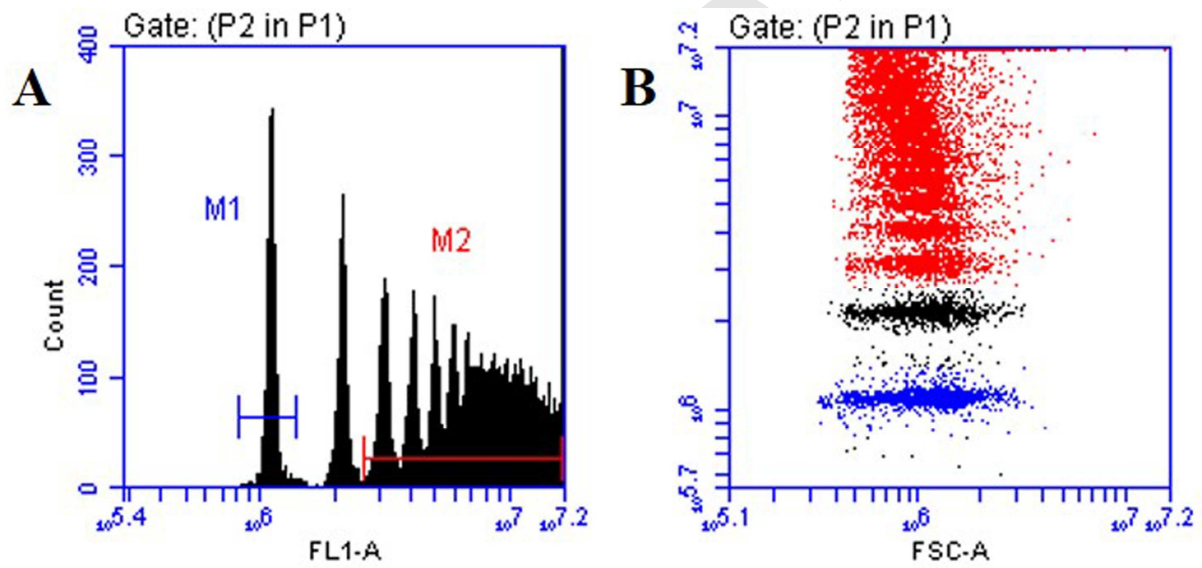

$1061 \quad$ Fig.4 

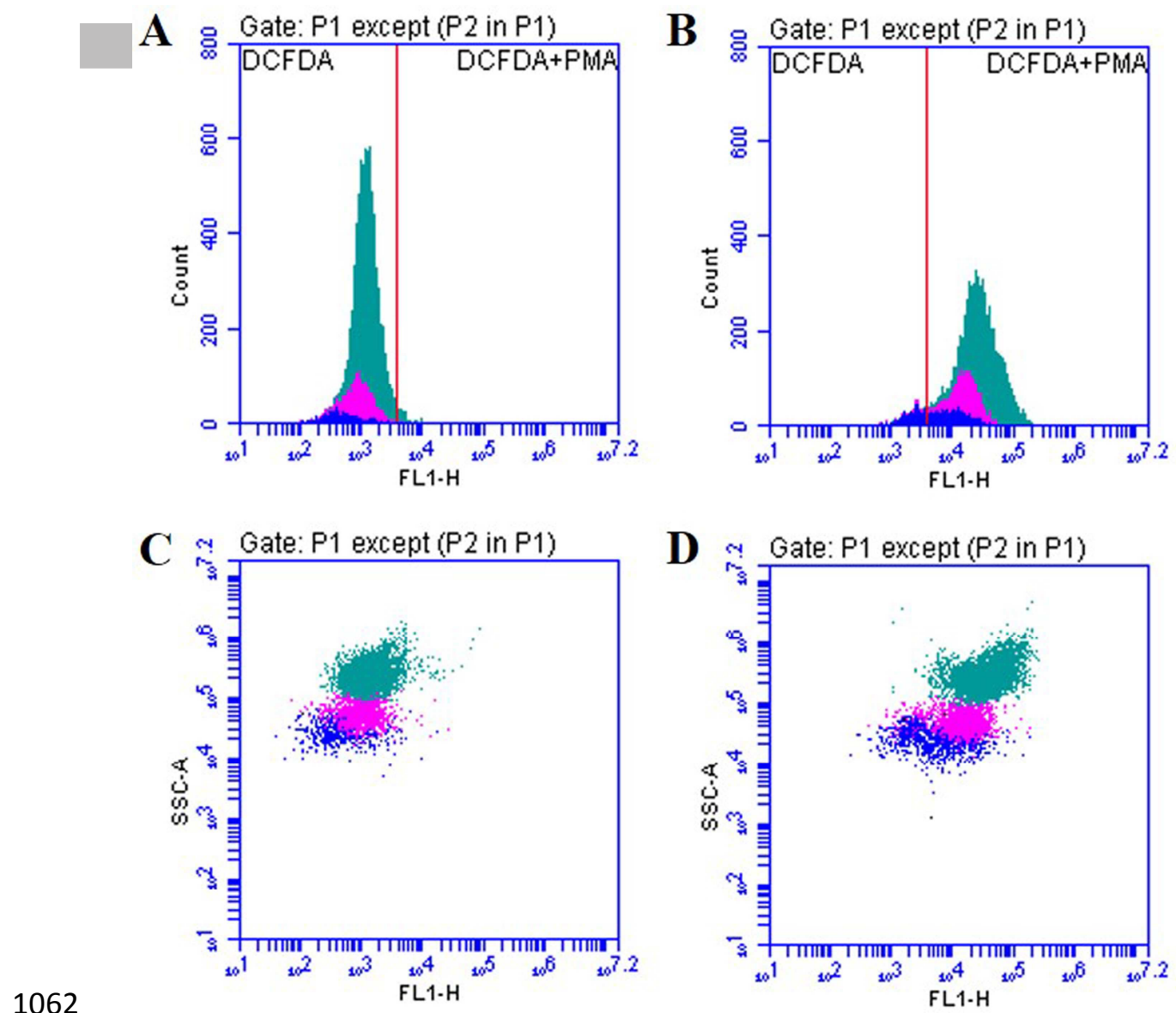

$1063 \quad$ Fig.5 


\section{No incubation}
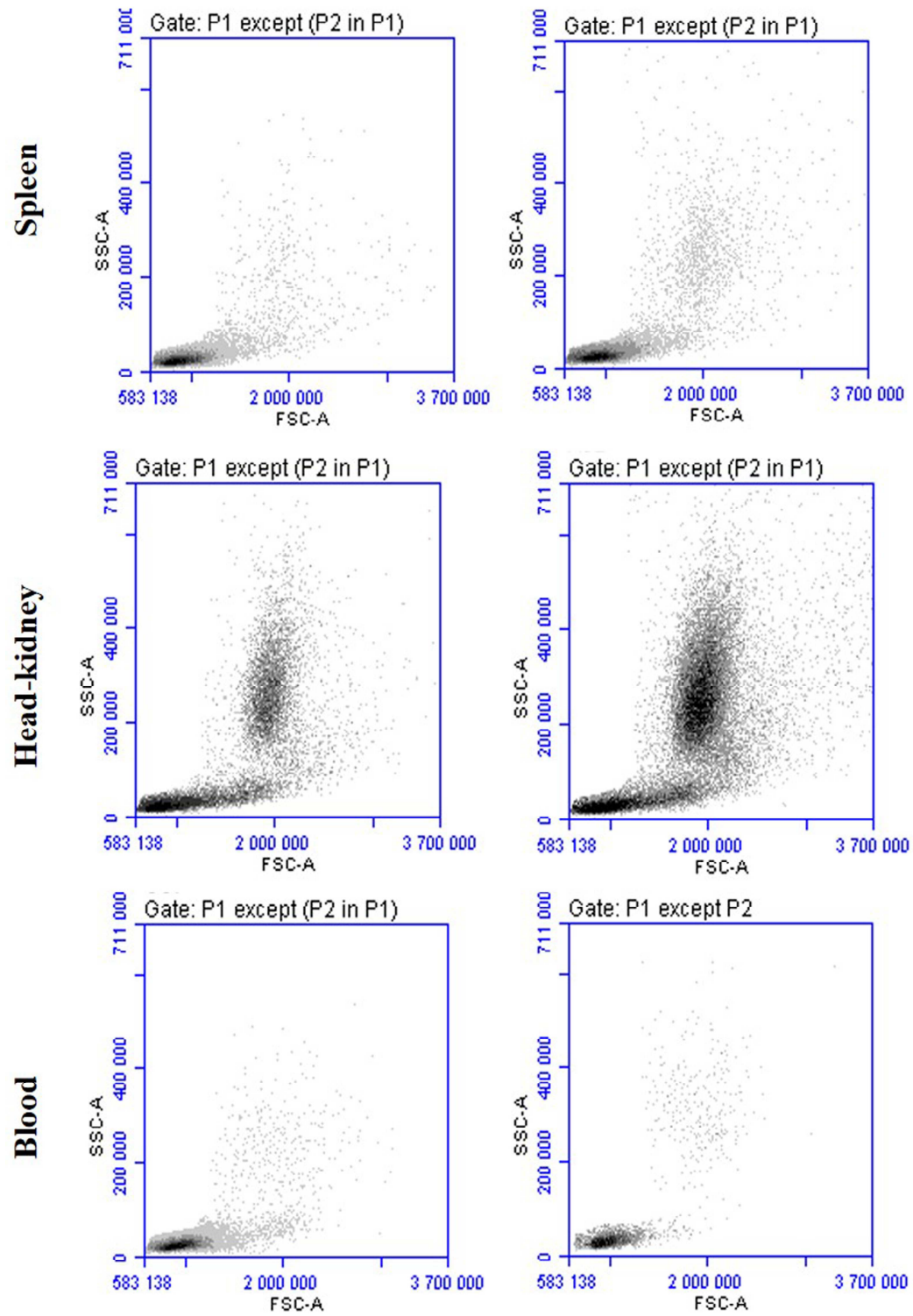

Hypotonic lysis

\section{$12 \mathrm{~h}$ incubation}
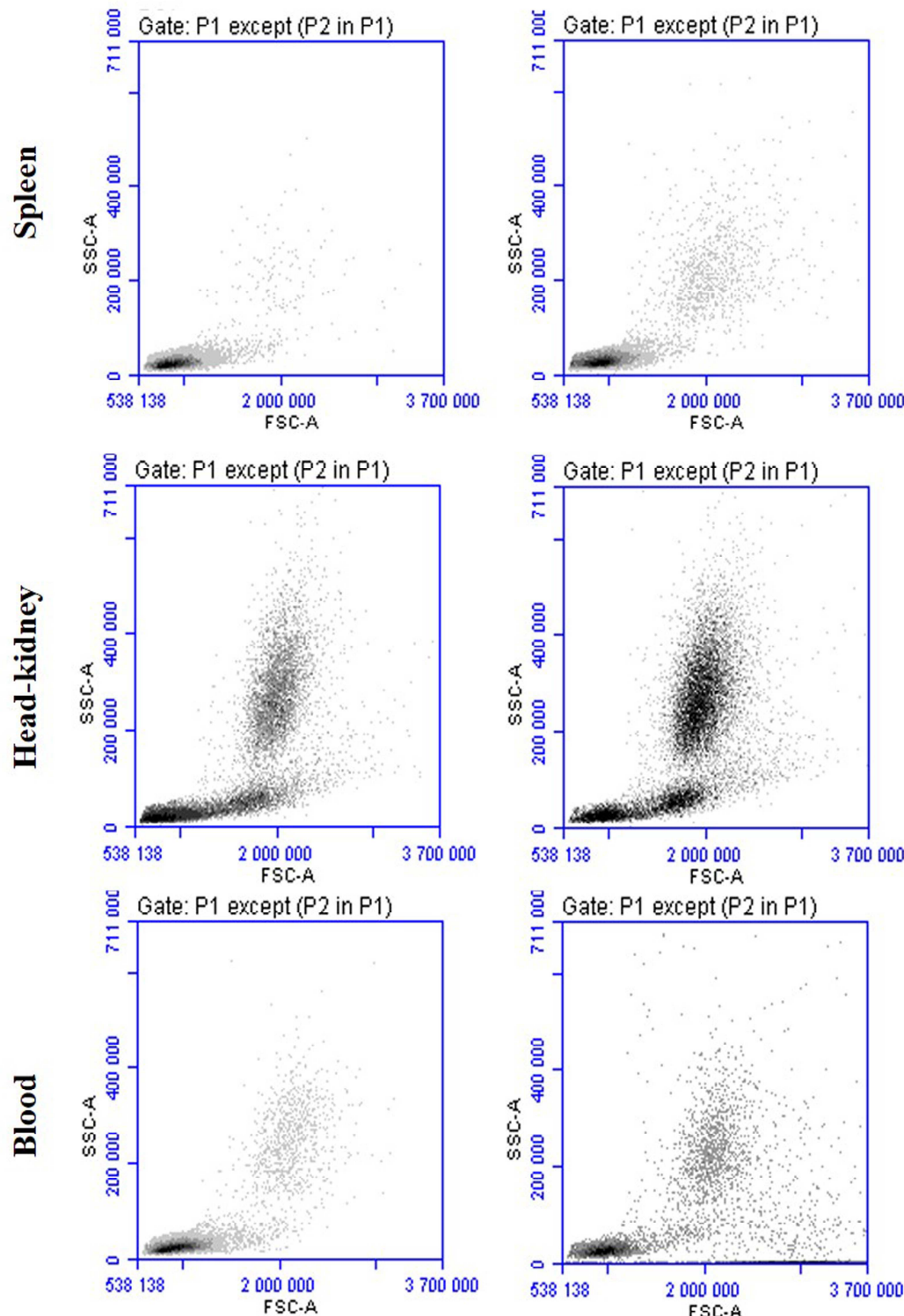

Density gradient

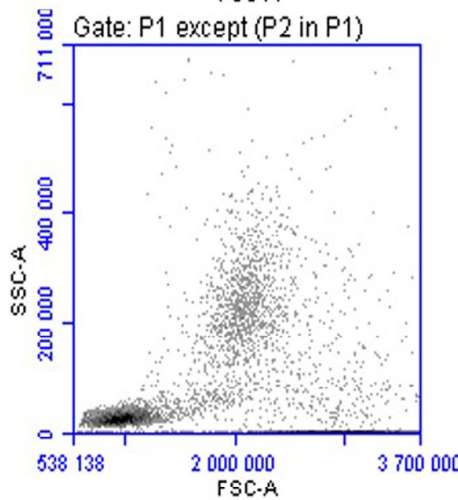

Hypotonic lysis 


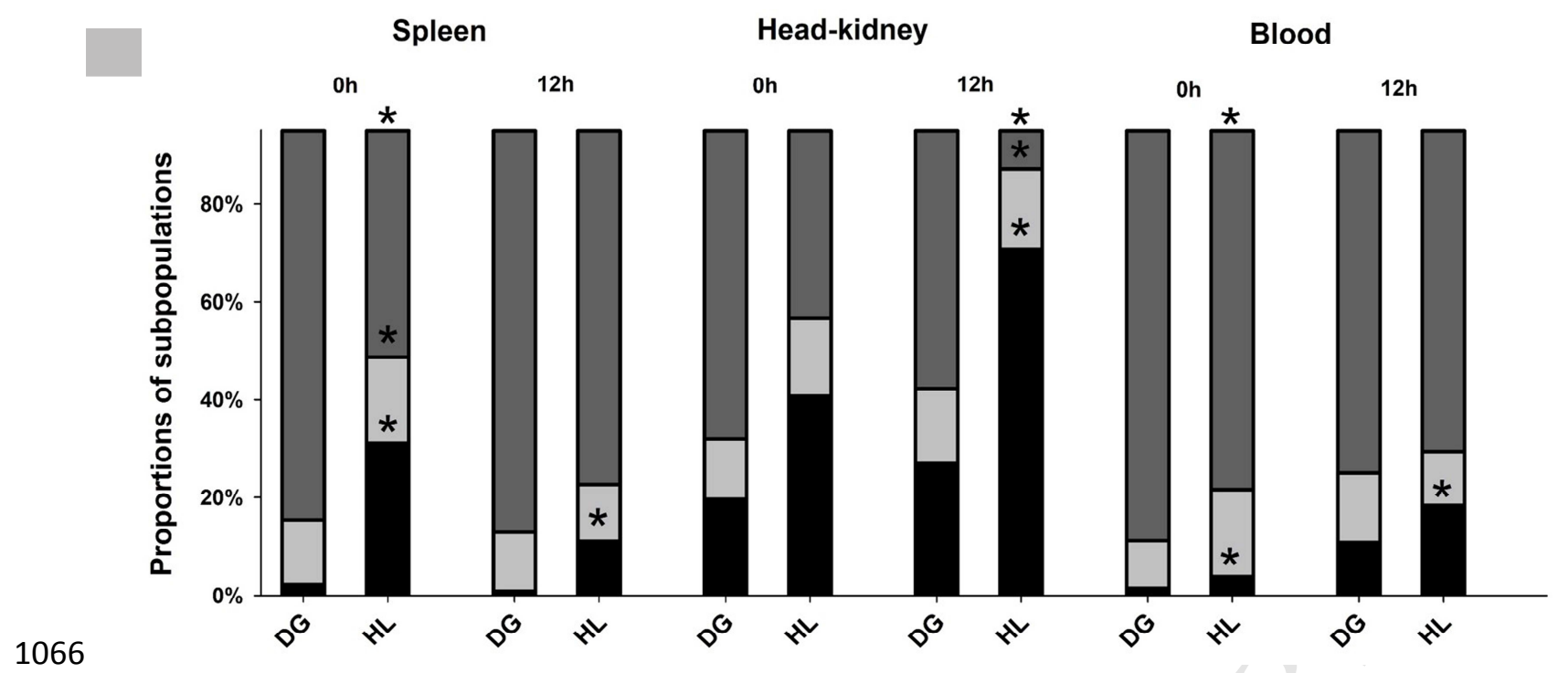

$1067 \quad$ Fig.7 


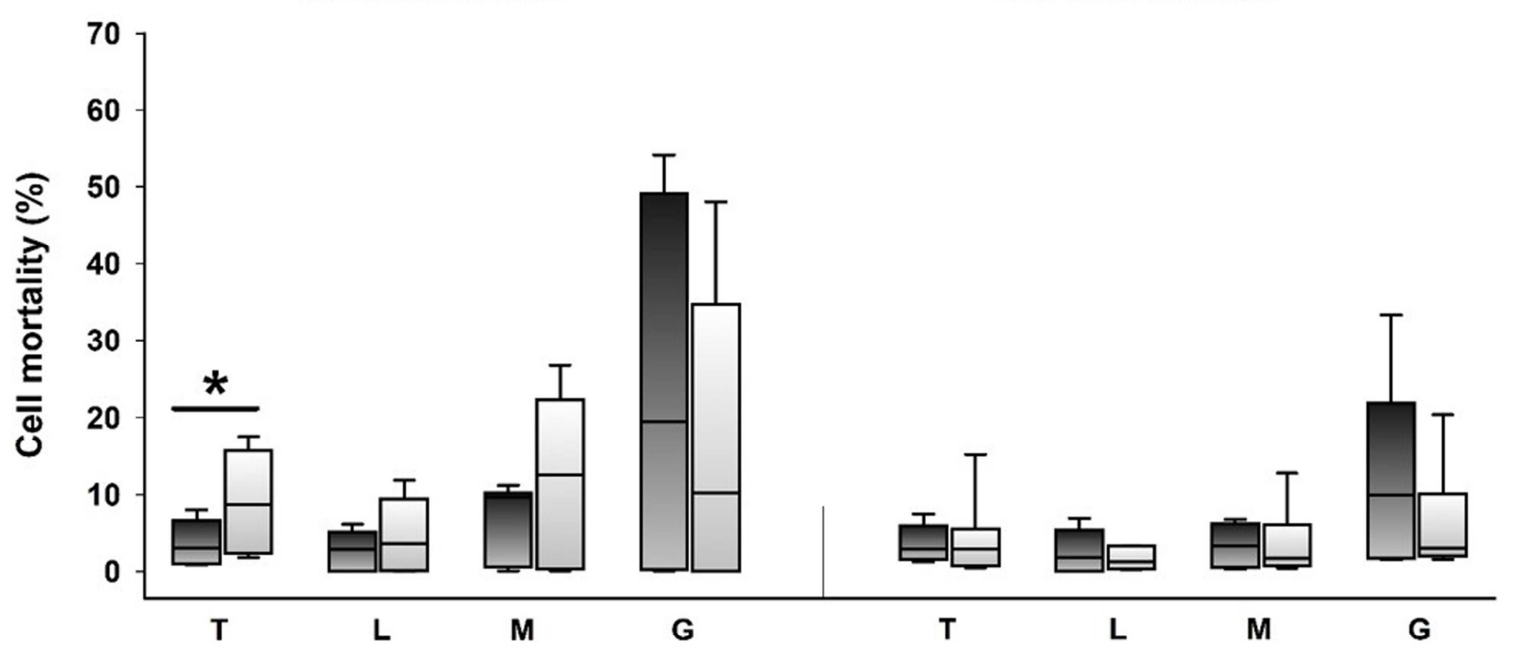

B

No incubation

$12 \mathrm{~h}$ incubation

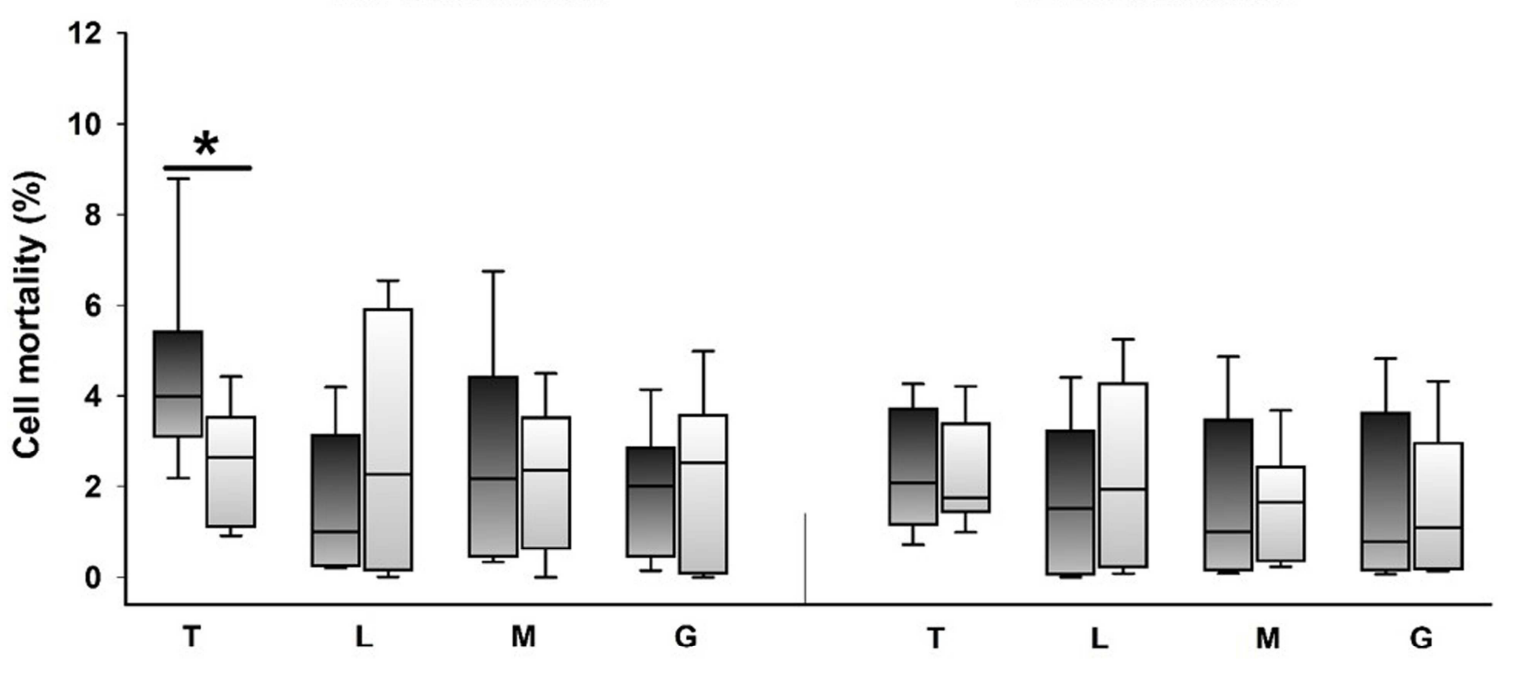

C

No incubation

12h incubation

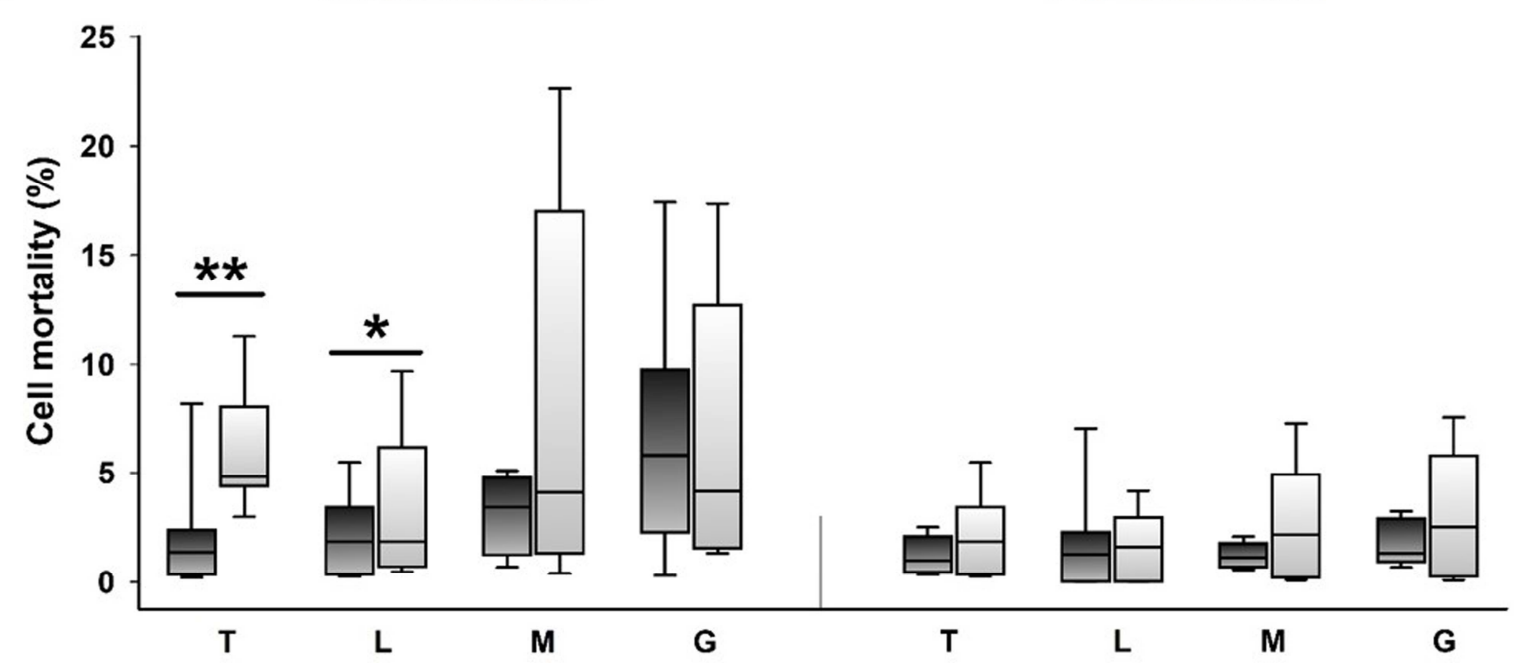

Fig.8 

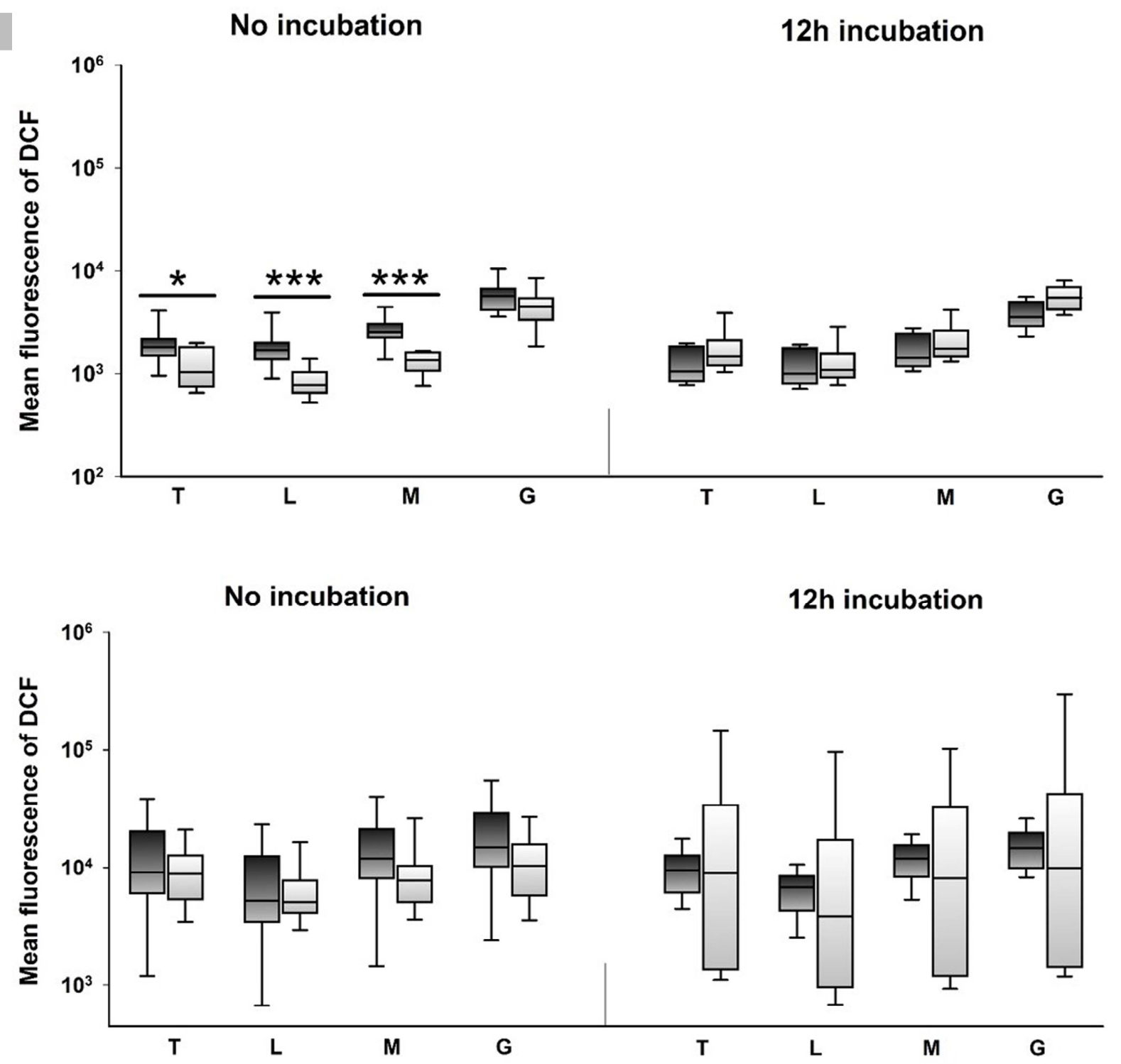

1070

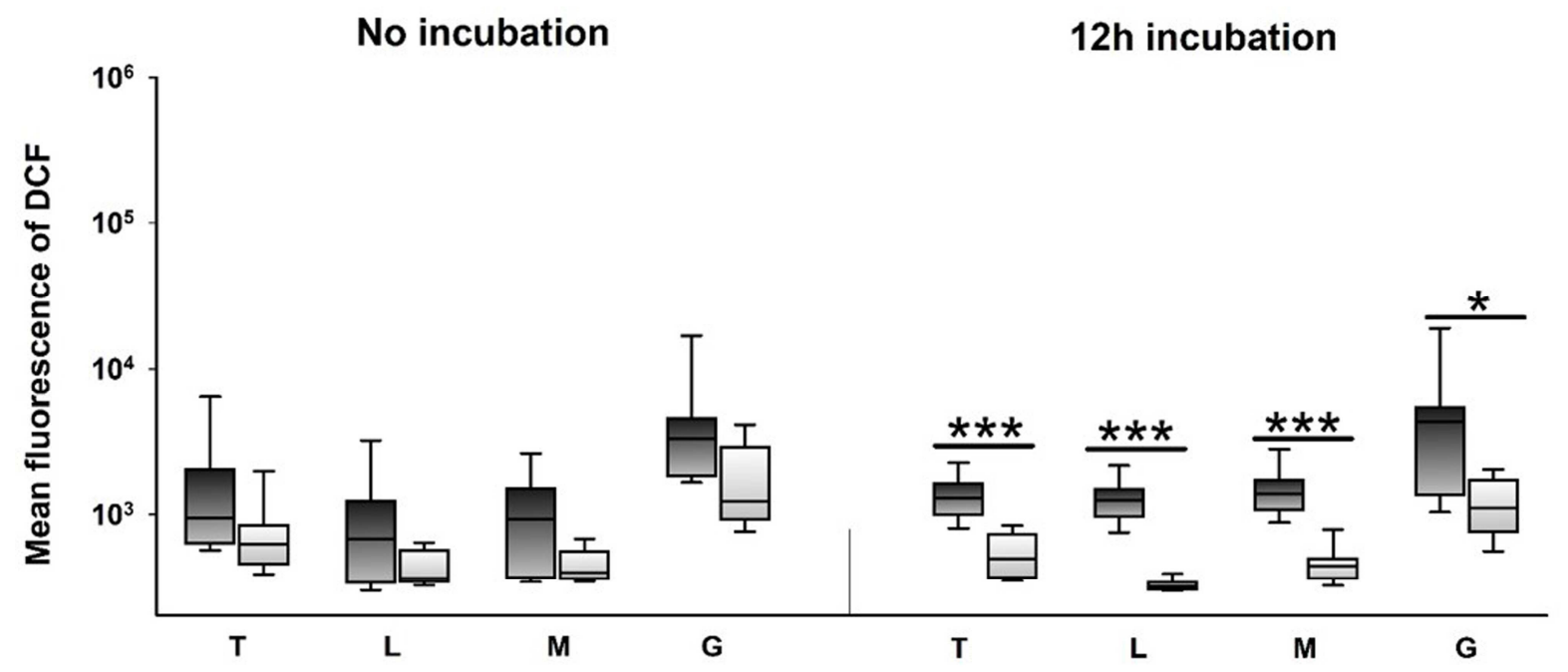

$1071 \quad$ Fig.9 
Highlights:

- Leukocytes purified from spleen, head-kidney and blood of roach by hypotonic lysis shows heterophils enrichment in contrast to density gradient.

- Cellular responses used for evaluation of fish immune status were influenced by procedures used for leukocytes isolation.

- Spleen was the lymphoid tissue whose leukocytes were the lowest influenced by isolating procedure used. 